\title{
Klotho, Aging, and the Failing Kidney
}

\author{
Sarah Buchanan ${ }^{1}$, Emilie Combet ${ }^{2}$, Peter Stenvinkel ${ }^{3}$ and Paul G. Shiels ${ }^{1 *}$ \\ ${ }^{1}$ Wolfson Wohl Cancer Research Centre, Institute of Cancer Sciences, University of Glasgow, Glasgow, United Kingdom, \\ ${ }^{2}$ School of Medicine, Dentistry \& Nursing, Human Nutrition, Glasgow Royal Infirmary, Glasgow, United Kingdom, ${ }^{3}$ Division of \\ Renal Medicine M99, Department of Clinical Science, Intervention and Technology, Karolinska Institutet, Stockholm, Sweden
}

OPEN ACCESS

Edited by:

James Harper,

Sam Houston State University,

United States

Reviewed by:

Stefanie Krick,

University of Alabama at Birmingham,

United States

Marc Vervloet,

VU University Medical

Center, Netherlands

*Correspondence:

Paul G. Shiels

paul.shiels@glasgow.ac.uk

Specialty section:

This article was submitted to

Endocrinology of Aging,

a section of the journal

Frontiers in Endocrinology

Received: 11 June 2020

Accepted: 09 July 2020

Published: 27 August 2020

Citation:

Buchanan S, Combet E, Stenvinkel $P$ and Shiels PG (2020) Klotho, Aging,

and the Failing Kidney.

Front. Endocrinol. 11:560

doi: $10.3389 /$ fendo.2020.00560
Klotho has been recognized as a gene involved in the aging process in mammals for over 30 years, where it regulates phosphate homeostasis and the activity of members of the fibroblast growth factor (FGF) family. The $\alpha$-Klotho protein is the receptor for Fibroblast Growth Factor-23 (FGF23), regulating phosphate homeostasis and vitamin D metabolism. Phosphate toxicity is a hallmark of mammalian aging and correlates with diminution of Klotho levels with increasing age. As such, modulation of Klotho activity is an attractive target for therapeutic intervention in the diseasome of aging; in particular for chronic kidney disease (CKD), where Klotho has been implicated directly in the pathophysiology. A range of senotherapeutic strategies have been developed to directly or indirectly influence Klotho expression, with varying degrees of success. These include administration of exogenous Klotho, synthetic and natural Klotho agonists and indirect approaches, via modulation of the foodome and the gut microbiota. All these approaches have significant potential to mitigate loss of physiological function and resilience accompanying old age and to improve outcomes within the diseasome of aging.

\section{Keywords: Klotho, aging, kidney, phosphate, senotherapeutic}

\section{INTRODUCTION}

In 1997 Kuro-o et al. (1) reported a mutant mouse displaying a phenotype similar to that of premature aging in humans. The phenotype of shortened lifespan, multiple organ degeneration, vascular calcification (VC), cardio-vascular disease (CVD) and frailty were attributed to the abolished expression of the klotho gene, named after the Greek goddess of fate, $\kappa \lambda \omega \theta \dot{\omega}$, who spun the thread of life (1). Subsequent murine models, deficient in Klotho, displayed both an accelerated aging phenotype and abnormal phosphate and mineral regulation $(2,3)$.

Klotho has subsequently been characterized as one of a family of related proteins. These are all single-pass transmembrane proteins that include $\alpha$-, $\beta$-, and $\gamma$-Klotho isoforms (3-5), the latter two discovered based on their homology with $\alpha$-klotho $(6,7) . \beta$-Klotho is mainly expressed in the liver, but is also found in the kidney, gut and spleen. It regulates the activity of members of the fibroblast growth factor (FGF) family, including FGF-21 and FGF-19. $\curlyvee$-Klotho is expressed in the skin and the kidney and has yet to be ascribed defined functions $(3,7)$. $\alpha$-Klotho comprises five exons and structurally its cognate protein is composed of a large extracellular domain followed by a transmembrane domain and a small domain of 11 residues comprising the intracellular C-terminus $(8,9)$. The extracellular domain comprises two repeat sequences termed KL1 and K12 which are generated by full-length transcript splicing and can be cleaved by the metalloproteases ADAM-10 and ADAM-17. Cleavage of the extracellular domain results in a soluble form of Klotho being released (8). Soluble Klotho is the main functional form in the circulation $(10,11)$ and is detected in the blood, urine, and cerebrospinal fluid (11-14). 
Following the discovery of $f g f 23$ deficient mice displaying an identical aging phenotype to Klotho deficient mice, the Klotho protein was functionally identified as a receptor for Fibroblast Growth Factor-23 (FGF23) (2). FGF23 is a bonederived hormone with a role in regulating phosphate excretion, which negatively regulates Vitamin D levels (15). Klotho is required for high affinity binding of FGF23 to its receptor FGFR1 (16); it is the resultant binary complex that constitutes the physiological receptor for FGF23 (17).

The Klotho protein that was identified as the FGF23 coreceptor was the $\alpha$-Klotho isoform, which hereafter is termed Klotho. Klotho is expressed mainly on the cell surface membrane of proximal and distal renal tubules (18-20), though it is also found in the choroid plexus in the brain (21).

\section{WHY KLOTHO IS IMPORTANT IN AGING}

Klotho regulates many pathways involved in aging processes, such as the regulation of phosphate homeostasis, insulin signaling and Wnt signaling $(5,22)$. Additionally, Klotho also affects intracellular signaling pathways including p53/p21, cAMP, protein kinase C (PKC) and TGF- $\beta(23,24)$.

Klotho expression levels and its circulating level decline during aging. In humans, Klotho deficiency features medial calcification, intima hyperplasia, endothelial dysfunction, arterial stiffening, hypertension, impaired angiogenesis, and vasculogenesis (i.e., characteristics of early vascular aging) (25).

As Klotho-deficient phenotypes have been attenuated and rescued by Klotho gene expression, or supplementation, it is suggestive that Klotho has a protective effect with regard to the vasculature (26).

Mice deficient in Klotho exhibit a phosphate imbalance and hyperphosphatemia due to impaired urinary phosphate excretion, but significantly develop a complex progeric phenotype including poor growth, atrophy of multiple organs, vascular calcification (VC), sarcopenia, cardiac hypertrophy and fibrosis, cognitive impairment, and shortened lifespan $(1,2,5)$. Consequently, Klotho knock-out mice display severe vascular disease, with widespread VC, endothelial dysfunction, and progressive atherosclerosis accompanied by hypervitaminosis $\mathrm{D}$, hypercalcemia, and hyperphosphatemia (27).

As Klotho has been regarded as an anti-aging gene, in order to more fully understand how Klotho might impact age-related disease, this review focuses on what we actually mean by the aging process, its relevance to chronic kidney disease (CKD) as a disease of accelerated aging, and how this is impacted by Klotho. Furthermore, we discuss how modulation of Klotho might be exploited to mitigate the effects of the diseasome of aging.

\section{Aging}

Rather than simply being a collection of morbidities arising during the final decades of life, aging is an active process across the entire life-course. It has been described as an accumulation of physiological and molecular deficits accruing at different rates, both within different tissues and organs in the same individual and between different individuals (28). Aging leads to a segmental and progressive loss of physiological function and physical capability over time, resulting in relative physiological frailty and loss of resilience (29-33). It is regulated actively by distinct biochemical pathways and has been characterized by a series of molecular and cellular hallmarks, which are common across taxa (33). These hallmarks comprise genomic instability, telomere attrition, epigenetic dysregulation, loss of proteostasis, dysregulated nutrient sensing, mitochondrial dysfunction, cellular senescence, with an accompanying senescence associated secretory phenotype (SASP), stem cell exhaustion, and altered intercellular communication (33).

\section{Aging and Phosphate-FGF23-Klotho Axis}

In mammals, aging has a number of distinct additional features to its common hallmarks, comprising phosphate toxicity, diminished global Nrf2 expression, and microbial dysbiosis (34). These features are inherent in an associated "diseasome of aging," where dysregulated aging processes are a common underpinning feature of individual morbidities. These reflect an individual's "burden of lifestyle" and the generation of allostatic (over)load at a molecular and cellular level, with concomitant loss of physiological resilience and capability $(34,35)$. It is within this framework that phosphate makes a significant contribution and why its interaction with Klotho is important.

Serum phosphate (Pi) levels shows an exceptionally strong negative correlation with lifespan in mammals (32, 36), Phosphate metabolism and reabsorption by the kidney is regulated via interaction between the kidney, bone, and gut, controlled by a cross-regulating endocrine network comprising para-thyroid hormone $(\mathrm{PTH})$, vitamin $\mathrm{D}, \mathrm{FGF}-23$, and Klotho (5). As mice lacking $\alpha$-Klotho, or FGF23, show phosphate retention (37), this suggests that this signaling axis is essential for Pi homeostasis. Several studies have shown that FGF23 increases urinary excretion of $\mathrm{Pi}$ and indirectly suppresses intestinal $\mathrm{Pi}$ absorption via down-regulation of vitamin D3 (15, 38, 39). Unsurprisingly, both FGF23 and Klotho deficient mice display a progeric phenotype and associated abnormal Pi regulation $(2,3)$. Additionally, Klotho deficient mice also display high FGF23 levels (40), and as a consequence of loss of Klotho expression may result in maladaptive signaling downstream of the FGF-receptor (FGFR) that may contribute to CKD associated co-morbidities, in particular cardiovascular co-morbidity. For example, this may result in a switch in FGF23-induced signaling in cells expressing FGFR4, but not $\alpha$-Klotho (40). Critically, in support of this thesis, specific FGFR4 blocking antibodies have been demonstrated to attenuate left ventricular hypertrophy $(\mathrm{LVH})$ in 5/6 nephrectomized rats, emphasizing that FGFR4 activation is a critical patho-mechanistic feature underlying $\mathrm{LVH}$ in states of $\alpha$-Klotho deficiency and elevated levels of FGF23 excess (41).

Pertinent to these observations are observations of Klotho signaling independent of FGFR4 in the heart, liver, and lung $(40,42)$. In the kidney context dependent signaling has also been reported; neither FGFR3 nor FGFR4 is the principal mediator of FGF23 effects in the proximal tubule, but co-localization of FGFR1 and Klotho indicates that the effector site for FGF23 may be in the distal tubule (43). A reduction in tubular phosphate 
reabsorption may enable hyperphosphatemia to occur at earlier stages of CKD.

It is unclear how changes in serum Pi are detected, however, it is thought to involve sensing of calciprotein particles (CPPs), which are colloids comprised of calcium-Pi bound to fetuin A, a circulating inhibitor of vascular calcification $(5,37,44)$. In proximal tubules, blood-borne FGF23 binds to $\alpha$-Klotho-FGF receptors $1 c, 3 c$, and 4 complexes, directly activating ERK $1 / 2$ and SGK-1 signaling cascades, leading to down-regulation of the $\mathrm{Na} / \mathrm{H}$ exchange regulatory cofactor NHERF-1 expression, localized to the brush border membrane of proximal tubular cells, a major site of Pi reabsorption (38). Down-regulation of NTP2A results in decreased Pi reabsorption in proximal tubules and increased urinary Pi excretion $(8,45)$. Active vitamin D and PTH both induce FGF23 expression $(46,47)$. Vitamin D has been shown to induce receptor hetero-dimerization with the retinoid receptor, resulting in the up-regulation of vitamin $\mathrm{D}$ responsive element target genes including FGF23 (48). PTH binding to its receptor results in PKA activation and the suppression of sclerostin, antagonizing the WNT signaling pathway and the suppression FGF23 expression (49). Serum levels of both active vitamin D and PTH are both reduced by FGF23, whilst FGF23 suppresses the synthesis of active vitamin D by up-regulation of Cyp24a1, which encodes 24-hydroxylase, responsible for the conversion to inactive vitamin $\mathrm{D}$ by a Klotho dependent mechanism (Figure 1). Cy27b1 expression, which converts the D3 form to the active form of vitamin D, is downregulated. PTH is suppressed via both $\alpha$-Klotho dependent and independent pathways. $\alpha$-Klotho is expressed in the parathyroid gland and FGF23 suppresses both the expression and secretion of PTH (46). Serum levels of FGF23 correlates with both serum Pi and calcium levels and evidence suggests that both $\mathrm{Pi}$ and calcium are required to stimulate FGF23 levels by osteocytes $(50,51)$. Notably, hyperphosphatemia has been shown to induce DNA damage in vascular smooth muscle cells, resulting in cellular senescence, which further contributes to the premature aging process observed with Klotho dysregulation or loss $(3,52)$. This has implications for clinical conditions where Klotho may play a role. This is now discussed below with specific reference to CKD as a disease of aging.

\section{CKD and Aging}

CKD is part of the diseasome of aging and displays an overlapping phenotype with Klotho-deficient mice. It has been suggested that Klotho function is tightly correlated with the pathogenic mechanisms underpinning CKD (18, 53-55).

CKD is a progressive systemic disease that affects $10-12 \%$ of the population (56). The prevalence of CKD has increased markedly over the past decades due to an aging population worldwide and an increase in incidence of obesity and type- 2 diabetes; a significant driver of CKD (57). Progressive kidney damage leads to an increased number of systemic complications, hallmarked by persistent (chronic) low-grade inflammation, including hyperphosphatemia, CVD, anemia, hypertension, mineral-bone disorders, muscle wasting, osteoporosis, increasing frailty, and anemia (58). In earlier stages of CKD, a reduction in the reabsorption of $\mathrm{Pi}$ by the kidney triggers increased FGF23 secretion that promotes renal Pi secretion. However, when patients reach CKD stage 3 systemic hyperphosphatemia usually occurs, which contributes to systemic inflammation and VC leading to early vascular aging (EVA) (59). Hyperphosphatemia promotes endothelial dysfunction (60) and induces expression of the pro-inflammatory NFkB pathway (61). Impaired kidney function results in the accumulation of systemic nitrogenous compounds which leads to persistent inflammation involving both immune activation and immunosuppression (62). The uremic phenotype within $\mathrm{CKD}$ is characterized by an increased frequency of associated age-related complications, such as vascular stiffening, osteoporosis, muscle wasting, depression, cognitive dysfunction, and frailty $(58,63)$. A model of four key mechanisms has been proposed for the pathogenesis of premature aging based upon: (i) a persistent increase in allostatic load owing to oxidative stress, inflammation (inflammageing), and disturbances in sympathetic-vagal balance and circadian rhythm; (ii) activation of the stress resistance response which contributes to inhibition of anabolic pathways, increased protein catabolism, and tissue atrophy; (iii) disease-associated alterations that directly promote the aging process; (iv) defective antiaging mechanisms (58). If allostatic response mechanisms remain chronically activated, systemic complications then follow.

Chronic low-grade inflammation also contributes to the premature aging phenotype in CKD (64) and other "burden of lifestyle" diseases, such as chronic obstructive pulmonary disease (COPD), chronic heart failure (CHF), and rheumatoid arthritis (RA). These diseases exhibit phenotypic similarities that reflect premature biological aging (58). Correspondingly, features of cellular aging such as telomere attrition and accumulation of p16 positive senescent cells, are characteristic of CKD and other conditions within the diseasome of aging $(8,29)$. Unsurprisingly therefore, uremic inflammation resembles the systemic inflammation associated with aging effects on the immune system, termed "inflammageing" and similar pathogenic mechanisms have been observed in aging and CKD, specifically premature immunological aging (65). Associated with this is immunosenescence, which arises due to the chronic depletion of naïve $\mathrm{T}$ cells, $\mathrm{B}$ cells, and dendritic cells, an expansion of memory $\mathrm{T}$ cells, particularly pro-inflammatory CD4+CD28$\mathrm{T}$ cells, along with impaired neutrophilic phagocytic capacity and the loss of reno-protective factors, including Klotho and bone-morphogenic proteins, vascular rarefaction, and increased oxidative stress $(58,66)$. Reactive oxygen species (ROS) levels can also regulate signaling via the stress activated kinases, p38, and JNK. These pathways are often activated in aged tissues and contribute to inflammation and cellular senescence (67-70).

Along with systemic oxidative stress, mitochondrial dysfunction is a partner in crime, that links together with inflammation and the effects of uremic toxins to accelerate the aging process $(44,58,71,72)$. Two protein-bound uremic toxins, indoxyl sulfate (IS), and p-cresyl sulfate (pCS), not removed by conventional dialysis, are potent inducers of inflammation, oxidative stress, and vascular endothelial cell injury (73) and contribute to both the progression of renal impairment (74) and associated co-morbidities (75). Advanced Glycation End 


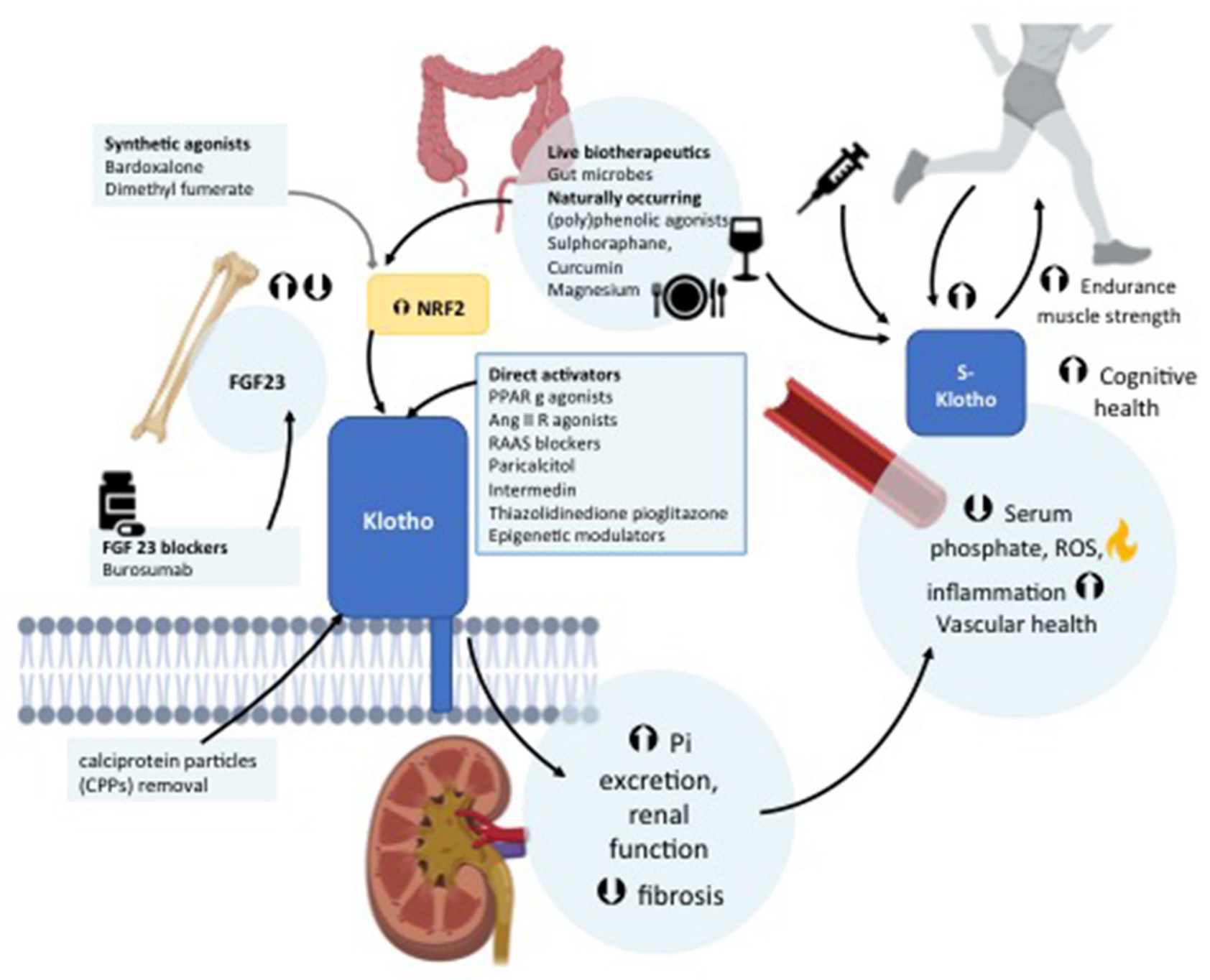

FIGURE 1 | Schematic representation of the role of Klotho in the regulation of bone and mineral metabolism.

Products (AGE), which are also uremic toxins, accumulate in $\mathrm{CKD}$, leading to mitochondrial dysfunction, elevated ROS production and structural changes through macro-molecular cross-linking. Consequently, the AGE axis induces renal cytosolic oxidative stress and inflammation $(76,77)$ leading to cell and tissue damage and the induction of premature senescence in proximal tubular epithelial cells and mesangial cells in vivo $(78,79)$.

A hallmark of uremic inflammation is the activation and defective regulation of the innate immune system. Abnormal activation of the innate immune system, especially the increased activation of monocytes, contributes to systemic inflammation via increased synthesis of pro-inflammatory cytokines. Several circulating pro-inflammatory markers have been reported to gradually alter in CKD as renal function fails, including IL6 , fetuin A, and TNF, which have previously been associated with renal aging and disease (80). Activation of inflammasome signaling by cytokines, ROS, and Damage-associated molecular patterns (DAMPs) results in an increase in Il-1 $\beta$ and IL-18, leading to an imbalance in the regulation of epigenetic mediators of aging such as miRNAs. For example oxidative stress has been shown to suppress Klotho expression in HK-2 cells via the induction of miR-200c (81). Deregulated TGF $\beta$ has also been shown to epigenetically induce Klotho deficiency and renal fibrosis in mice via induction of a number of miRNAs, including miR-21, miR-192, miR-491, miR-382, miR-377, miR214 , and miR-433 (82). The resulting imbalance of pro- and antiinflammatory macrophages, and mitochondrial damage leads to the chronic systemic uraemic inflammation associated with CKD (44). Additionally, a consequential increase in synthesis of proinflammatory cytokines and chemokines by senescent cells, as part of the senescence-associated secretory phenotype (SASP), exacerbates both the inflammatory burden and dysregulated aging processes in CKD (44). 


\section{KLOTHO IN CKD}

The phenotypic characteristics of genetic Klotho deficiency, such as bone disease, VC, CVD increased FGF23 levels, hyperphosphatemia, and premature mortality, resembles the uremic accelerated aging phenotype in man $(58,83)$. In keeping with these observations, Klotho deficiency in CKD has been reported to enhance renal tubule and vascular cell senescence leading to defective endothelial function and impaired vasculogenesis (84). Current literature supports such a thesis, and has indicated that the development and progression of CKD is significantly associated with a dysregulated FGF23Klotho pathway, resulting in hyperphosphatemia and endothelial dysfunction $(8,18,53-55)$. Phosphate retention, progressive hyperphosphatemia, rising FGF23 levels and low Klotho expression are all observed in patients with progressive CKD and are associated with age-associated CVD. Correspondingly, more recent studies have reinforced these observations and shown that the development and progression of CKD associates with a decline in Klotho in animal models $(18,53-55,85-$ 87). Kidney specific Klotho deficiency has been observed to reproduce the phenotype of Klotho deficient animals, displaying very low circulating Klotho and high circulating FGF23 levels (88). Specific deletion of Klotho in distal tubules has also been reported to inhibit the increase in renal Pi excretion in response to FGF23 (89), which suggests that Klotho deficiency limits its regulation of FGF23 production and that hyperphosphataemia, which usually become evident in $\mathrm{CKD}$ stage 3 , remains the principal regulator of FGF23 secretion in CKD (90).

Dysregulation of the FGF23- $\alpha$-Klotho network already occurs at earlier CKD stages, where abnormal levels of calcium and phosphate, inflammation, increased apoptosis, and depletion of calcification inhibitors results in the promotion of an active calcification process $(91,92)$. As nephron numbers decrease with age and renal damage, there is a resultant increase in Pi excretion per nephron via up-regulation of FGF23 observed in all CKD patients, causing a lowering of active vitamin $\mathrm{D}$ levels in the serum followed by an increase in PTH $(5,8,44,93,94)$.

Recent research has indicated that Klotho may be involved in the manifestation of comorbidities associated with CKD. Klotho, for example, is expressed in the choroid plexus of the brain and controls the brain-immune system interface in the choroid plexus (21). As the uremic phenotype is associated by behavioral impairments, such as dementia, depression and cognitive deficits (95) and Klotho enhances oligodendrocyte maturation and myelination of the CNS (96), the low Klotho state of CKD may contribute to the common manifestations of central nervous system dysfunction in CKD. The specific role of the low Klotho state in the complicated scenario of uremic cognitive dysfunction (97) and disruption of the blood-brain barrier when renal function declines (98) deserves further studies.

Hypertension, an almost ubiquitous feature of CKD that contributes to both progression of CKD and CVD, may in part be related to Klotho deficiency. Mice deficient in Klotho have been reported to develop salt-sensitive hypertension after high sodium challenge (99) and a Klotho single nucleotide polymorphism with salt-sensitive hypertension has been described in adults with newly diagnosed hypertension (100).

In the uremic milieu lower Klotho levels may be exacerbated by the accumulation of protein bound uremic toxins, that epigenetically dysregulate Klotho gene expression and by an increase in TNF, which impairs Klotho protein expression $(5,29,101)$. This relationship with inflammatory processes appears to be mutually reciprocal. Klotho modulates antiinflammatory response in the kidney via a NF- $\mathrm{KB}$ mediated pathway, while Klotho expression in turn, is down-regulated by pro-inflammatory cytokines, such as TWEAK, again via an NF$\kappa \mathrm{B}$ dependent mechanism. Thus, while NF- $\mathrm{BB}$ per se contributes to the regulation of Klotho expression (102), Klotho however, in turn down-regulates NF- $\mathrm{kB}$ (103) and inhibition of NF- $\mathrm{kB}$ has been shown to reduce expression of several pro-inflammatory cytokines and renal injury (104-106). Correspondingly, in keeping with this thesis, Klotho depletion has also been shown to contribute to increased inflammation in the kidney in a preclinical murine model (107).

\section{Klotho and Vascular Biology}

Numerous studies have suggested that Klotho is critical for vascular health and its therapeutic administration in CKD can exert vasculo-protective effects. Vascular calcification develops early in CKD and is associated with a decline in kidney function and an up-regulation of Pi resulting in a high risk of cardiovascular mortality and morbidity $(8,108-110)$.

Accordingly, Klotho deficiency in mice with CKD is paralleled by the development of $\mathrm{VC}$ and the occurrence of high Pi levels. As over-expression of Klotho enhances phosphaturia and improves renal function, it is suggestive that dysregulation of Klotho function is a key element in the development of VC $(27,55)$.

Zhao et al. (111) have demonstrated that up-regulation of Klotho expression protects against VC in CKD, via the inhibition of mTOR signaling in VSMC, in keeping with CKD as a disease of accelerated aging $(111,112)$. Accordingly, the stable delivery of soluble Klotho has been reported to reduce chronic hyperphosphatemia and VC both in vitro and in vivo (113). In support of these observations, soluble Klotho has been demonstrated to directly suppress Pi uptake and mineralization induced by high Pi in vivo, whilst administration of recombinant Klotho increased soluble Klotho by vitamin D receptor agonists (VDRA) treatment. Accordingly, the stable delivery of soluble Klotho has been reported to reduce chronic hyperphosphatemia and VC both in vitro and in vivo (113). This is in keeping with data from other approaches to mitigate the effects of hyperphosphatemia driven VC. Lau et al., have demonstrated that in a mouse model of chronic kidney disease where dietary phosphate loading induced aortic medial calcification, administration of vitamin D receptor agonists (calcitriol or paricalcitol) reduced aortic calcification and increased the expression of the anti-calcification factor, osteopontin, in aortic medial cells $(27,114)$.

CKD-mineral Bone disorder (CKD-MBD) and renal fibrosis have both been associated with diminished Klotho expression. Studies in a mouse model of CKD-MBD have indicated that loss of Klotho expression is a key event in renal and bone injuries 
and that restoration of Klotho expression attenuated CKD related bone defects (115). These observations are supported by enhanced Klotho expression via differential promoter demethylation, which has been demonstrated to protect against kidney and bone injuries in a mouse CKD model (116). Renal fibrosis, is also affected by Klotho expression levels. Renal fibrosis occurs following incomplete healing of wounded kidney tissue in the course of CKD, after chronic sustained injury. It is characterized by glomerulosclerosis, tubular atrophy, and interstitial fibrosis (117). A reduction in Klotho can both be a result and cause of renal fibrosis and can promote a vicious circle of RF generation and mitigation (118). A key regulator of this renal fibrosis cycle in CKD is TGF- $\beta$, which stimulates the accumulation of matrix proteins to induce ECM, inhibition of matrix degradation and the regulation of myofibroblast activation (119). In keeping with this thesis, murine models have indicated that inhibition of Klotho increases TGF- $\beta$ expression and that TGF- $\beta$ subsequently reduces Klotho expression via a negative feedback loop (120). Induction of Klotho also directly mitigates the effects of other pro-fibrotic factors, such as Angiotensin II (Ang II) and basic Fibroblast growth factor 2 (bFGF2). Klotho has been reported to mitigate Ang II-induced renal damage and suppress bFGF 2 expression in vivo (121) in keeping with a proposed reno-protective role for Klotho via the inhibition of multiple signaling pathways.

\section{DISCUSSION}

The weight of basic science, pre-clinical, and clinical evidence suggests that modulation of Klotho function is an exciting and viable target for therapeutic interventions. As such, it is a prime therapeutic target for intervention in a range of diseases within the diseasome of aging, including $\operatorname{CKD}(8,122,123)$. Given the role of Klotho in the biology of aging, such interventions also fall within the remit of senotherapies (i.e., therapeutic agents and strategies to specifically target and mitigate the deleterious effects of aspects of aging process).

As such, Klotho-mediated therapies may be classed as geroprotective (i.e. mitigating or inhibiting the effects of macromolecular damage leading to loss of cellular and physiological resilience and function, including the effects of the SASP), and senomorphic (i.e. suppression of senescence effects without cytotoxicity). It is important to note, however, that the context of their application and time in the life course applied are key elements for any success. While most basic and preclinical studies have focussed on mid- to end of life application, data from early life interventions are sparse and require a more robust evaluation. This is pertinent to the concept of antagonistic pleiotropy, as aging is a continuous process occurring across the life course, thus suggesting that the effects of any interventions will be dependent on the context of the stage of the life course at which they are applied. Cellular senescence is likely to be subject to antagonistic pleiotropy, as senescent cells are not desirable in young individuals, but are essentially anti-oncogenic in the old. The potential for any intervention to generate adverse effects, especially subtle epigenetic or cryptic effects, thus needs evaluated from this perspective. Initial evidence, however, suggests that most interventions appear to be well-tolerated and have some beneficial effective. Indeed, over-expression of $\alpha$ Klotho has been reported to reverse the phenotype and extended life-span in Klotho-deficient mice $(11,114,124)$.

Targeting Klotho in CKD is particularly pertinent on a number of fronts, Firstly, accurate detection of CKD at an early stage has proven problematic and currently no biomarkers are available which are suitably accurate, easily measured and sensitive enough (125). Current diagnostics rely on a GFR and urinary albumin:creatine ratio (UACR) (88). Thus, a blind spot occurs in early stage CKD where the eGFR and albuminuria are not above abnormal thresholds although kidney damage is ongoing. Soluble Klotho starts to decline in early CKD (Stage 2) (20). The decrease in Klotho in the kidneys correlates positively with diminution of eGFR (126129), suggesting the decrease in soluble Klotho may accurately mirror an eGFR decrease in patients. Thus, measuring Klotho levels may provide earlier diagnosis (130). Secondly, standardized functional assays to detect Klotho activity are still currently lacking and several commercially available antibodies have been reported as unspecific and to cross-react with other proteins $(131,132)$. Thirdly, a number of strategies have been attempted to modulate Klotho expression with the aim if clinically translating findings. These strategies are illustrated in Figure 2 and are now discussed.

\section{Restoration of Klotho Levels and Activity Administration of Exogenous Klotho}

Several studies have suggested that pharmaceutical replacement or supplementation of Klotho can improve complications associated with CKD (8). Pre-clinical studies have indicated that administration of soluble Klotho can reduce renal fibrosis (120), VC (133), and EMT (134). Administration of soluble Klotho has proven a safe and effective treatment for kidney injury and preservation of renal function in early clinical studies (20, 135), though subsequent use of recombinant Klotho has yielded equivocal results (136).

\section{Reactivation of Endogenous Klotho}

Activation of Klotho has been reported to reduce levels of oxidative stress (137), improve mitochondrial function (137), reduce renal fibrosis (138), and inflammatory burden (8). Additionally it has been reported to mitigate the effects of premature aging (137) and EVA (139). Several methods have been explored to increase Klotho expression. These include:

(i) Demethylation of the Klotho promoter: Azuma et al. have demonstrated the use of Azacytidine (Aza), a DNA methyltransferase inhibitor, to increase Klotho expression $\sim 1.5$ - to 3 -fold in vitro by modulation of Klotho promoter expression (140). While this is feasible the laboratory, its clinical translation is more challenging, given the broad spectrum activities of Aza.

(ii) Deacylation: Inhibition of histone deacetylases using HDAC inhibitors, such as trichostatin A or valproic acid have 


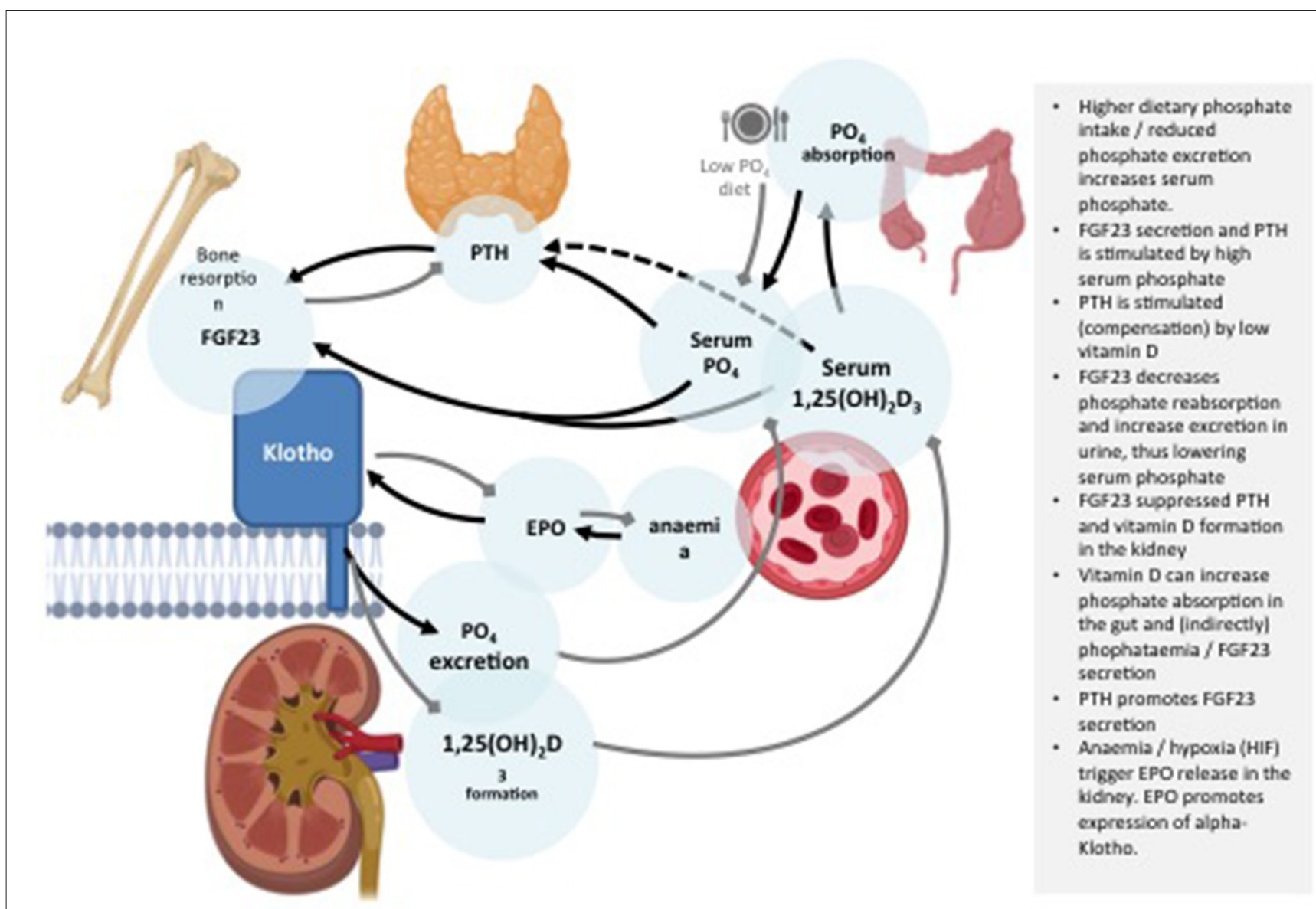

FIGURE 2 | Schematic representation of a range of possible and existing Klotho based senotherapies.

been shown to reduce inhibition of Klotho expression by TNF/TWEAK signaling in the kidney (86).

(iii) PPAR-c antagonism: The PPAR- $\gamma$ agonists troglitazone and ciglitazone, have been shown to increase both Klotho mRNA and protein expression in vitro. This induction was blocked by PPAR-c antagonists or by small-interfering RNA-mediated gene silencing of PPAR-c, suggesting this is a PPAR-c-dependent mechanism (141).

The angiotensin II type 1 (AT1) receptor is also important in the aging process. Activation of the AT1 receptor by AngII is implicated in the age-related developments of hypertension, diabetes, and kidney disease. Disruption of the AT1 receptor gene in mice extends life-span and lowers levels of oxidative stress (142). Angiotensin II-type I receptor agonists have been used to demonstrate that cyclosporin-induced renal injury decreased Klotho expression. Yoon et al. have demonstrated that the Inhibition of the renin-angiotensin system (RAS) with Losartan restored Klotho expression in chronic CsA nephropathy (143). RAAS-blockers which block angiotensin/aldosterone have also been reported to reverse diminution of Klotho expression in rodents $(5,20,144)$.

(iv) Vitamin D derivatives e.g. paricalcitol: which has been shown to induce Klotho expression in rodent CKD models $(145,146)$. Another is Intermedin-a member of calcitonin family, which is thought to play a role in angiogenesis (147). Thiazolidinedione pioglitazone (designed to reduce insulin resistance by increasing peripheral glucose disposal and decreasing glucose production) resulted in increased expression of Klotho and protection against renal injury in aging (8). Statins have also been shown to induce Klotho mRNA expression (8).

(v) Exogenous recombinant peptide has also been used to raise soluble $\alpha$-Klotho concentrations $(20,148)$ and supplementation with the peptide has been shown to attenuate LPS-induced kidney injury in mice (134). Numerous studies have shown that similarly to animals overexpressing $\alpha$-Klotho, administration of the peptide also improved renal fibrosis in UUO and bilateral IRI models $(10,120,121,135,148,149)$, cardiac fibrosis in mice following induced injury (10), and could reduce acute 
to chronic disease progression with development of post AKI-cardiomyopathy. It was also effective in models of established injury.

\section{FGF23 Blockade}

Blockade of FGF23 using Burosumab, has been demonstrated to be effective in control and improvement of rickets in patients with X-linked hypophosphataemia $(150,151)$. Use in CKD would require a very narrow and defined window of therapy to maintain phosphate balance. As FGF23 blockade in animal models resulted in worsened mineral balance and subsequent vascular abnormalities (152), more understanding of the FGF23phosphate balance required are needed.

\section{Exercise}

Numerous studies have demonstrated the effectiveness of exercise to prevent, reverse, or attenuate premature aging (58, $153,154)$. Exercise is associated with regenerative tissue response (155), reduced atherosclerosis (156), and type-2 diabetes risk (157). Specifically higher Klotho concentrations are associated with increased lower limb strength (158), a reduced likelihood of developing Alzheimers (14), resistance to oxidative stress (159), and a lower risk of CVD and mortality (160). In preclinical murine models, s-Klotho levels have been associated with muscle strength and endurance capacity (161). However, the response to exercise was shown to differ with age (162) and may be subject to antagonistic pleiotropy. In humans, however, a long-term exercise programme resulted in increased soluble Klotho levels being observed in both young and old participants (162). Levels of soluble Klotho were also shown to be higher in trained young and old subjects compared to untrained subjects (163), and aerobic exercise was reported to increase plasma Klotho levels in young subjects (164). However, in contrast to these reports despite a functional improvement during a rehabilitation program, Klotho levels have been reported to remain unchanged in COPD patients (165). Several components of physical fitness have been related to related to s-Klotho plasma levels in the InCHIANTI study, which was a cohort survey initiated in 1998, primarily to study risk factors and mechanisms of mobility loss and aging $(158,166,167)$. Evidence from general population cohort studies on the role of beta or gamma Klotho remains pauce. Optimal and comprehensive therapeutics strategies targeting Klotho might therefore still need to ensure address of each of individual isoforms to identify most the clinically beneficial isoform relative to a particular life course or disease contex. The concentration of circulating Klotho required, and that of each of its isoforms, will need to be precisely identified and genetic variability taken into consideration. High levels of Klotho could result in hyperparathyroidism and hypophosphatemic rickets (168), or have other toxic effects. Timing of Klotho delivery is also critical as soluble Klotho has been shown to be highly unstable in the blood and urine (169) and prevention of degradation may be essential.

Numerous compounds have been approved for use in CKD but with only some positive outcomes seen suggesting the extent of reactivating and or replacing Klotho and its effects are yet to be clarified (170).

\section{Nutrition}

A number of studies have intimated that Klotho expression is amenable to nutritional intervention. Age-related changes in Klotho gene expression, particularly renal Klotho expression, and vitamin $\mathrm{D}$ metabolism can be affected by dietary Pi intake. As such, nutritional acquisition of $\mathrm{Pi}$ can radically affect agerelated health, which opens up an easy avenue for therapy. There is good rationale for such an approach, as Pi has been linked to accelerated biological aging (including shortened telomeres, age related genomic hypomethylation) and poorer renal function (171) Higher all-cause and cardiovascular mortality risk have also been associated with Pi intake (172), and to accelerated vascular aging in the general population $(60,173)$. Additionally, in preclinical studies, high dietary Pi intake has been demonstrated to shorten life span in Klotho-deficient mice via activation of the AKT/mammalian target of rapamycin complex 1 (mTORC1) (174). Modulation of phosphate in the diet can be problematic. High protein foods tend to be high in phosphorus, and low phosphate diets present adherence challenges. Defining diets acceptable for patients is therefore an important focus. In a short phosphate restriction trial in patients with ESKD on hemodialysis, Tsai et al. have compared low and very low phosphate diets (phosphate:protein ratio 8 vs. $10 \mathrm{mg} / \mathrm{g}, 2$ days each, separated by 5 days washout). While both diets led to a decrease in phosphate level, which was more marked with the very low phosphate diet, no difference was noted in FGF23 levels between the two diets, which performed similarly in decreasing FGF23. Supplementation with ketoacid analogs (KA, analogs of amino acids without the amino group, converted to AA without additional nitrogen) has been proposed to mitigate the risk of nutritional disorders associated with very-low protein diets (VLDP). In a short crossover study in CKD patients (1 week on very low-protein diet $0.3 \mathrm{~g} / \mathrm{kg} / \mathrm{d}$ supplemented with ketoanalogues; 1 week on low-protein diet $0.6 \mathrm{~g} / \mathrm{kg} / \mathrm{d}$ ), Di Iorio et al. (175) have demonstrated a $\sim 34 \%$ decrease in FGF-23 following the VLPD + ketoanalogues. In patients with CKD 3b4, a 14 -months low protein diets $(0.6-0.8 \mathrm{~g}$ protein $/ \mathrm{kg} / \mathrm{d})$ was effective in decreasing BMI, at the expense of muscle mass, with no noted reduction on serum phosphate. In comparison, ketoacid analog supplementation of the LPD was effective to maintaining FGF23 and serum Klotho levels, while these increased and decreased, respectively, in absence of KA (176). After 14-month of ketoacid-supplemented LPD supplemented valvular calcification score was also lower compared to patients following the LPD diet only.

Other pre-clinical studies have indicated that a high fat diet (HFD) as a surrogate for an energy rich and calorie dense western diet, results in age-related alterations in renal $\alpha$ Klotho expression that could affect the responsiveness of dietary phosphate to vitamin D metabolism (177).

Alternative nutritional interventions have been designed to modulate Klotho-FGF23 inter-activity in CKD and thus address significant features associated with its pathophysiology including hyperphosphatemia, iron deficiency, and anemia [reviewed by (178)]. Interventions using iron therapies have displayed varied impact on Pi toxicity (179), though strategies involving ironbased phosphate binders do address the dual challenges of 
mitigating the effects of hyperphosphatemia and iron deficiency. In mice, ferric citrate administration (5\% ferric citrate enriched diet) has led to phosphate binding, correction of iron deficiency, reduced circulating FGF23, and improved CKD outcomes (180).

Recently, use of a high magnesium diet has been demonstrated to prevent extensive vascular calcification in Klotho knock-out mice, opening up a novel route to tackling clinical VC. These effects were potentially mediated by reduction of inflammatory and extracellular matrix remodeling pathways within the aorta. Notably, serum parathyroid hormone, 1,25-dihydroxyvitamin $\mathrm{D}_{3}$ and calcium levels were unaffected. However, the high magnesium reduced bone mineral density and presented treated animals with possible osteomalacia (181).

Use of magnesium in this context is not unsurprising, given that $\mathrm{Mg}^{2+}$ is a key factor in the regulation of telomere biology and its level in the body is diminished in many diseases of aging (182).

Poor quality diets have been linked with higher level of dietary phosphate additives, higher fat intake, low vitamin D status, and lower bioactive-rich fruit and vegetables.

There is a rapidly emerging link between diet and FGF23, with associations described between diet quality/food (in)security and FG23 levels. In young adults studied in the context of coronary artery risk development, this has been tested under the hypothesis that food insecurity would be associated with intake of food and drinks with higher levels of phosphate additives, with potential impact on increased levels of FGF23 as a compensatory response to higher dietary phosphate intake (183). Pool et al. (183) have shown that individuals transitioning toward lower food security (i.e., "developing food insecurity"- defined as being unable to secure food of sufficient quantity and quality), was associated with increased odds of high FGF23 expression levels. This study was however unable to associate phosphorus intake with odds of elevated FGF23 expression in the cohort, in the absence of chronic kidney disease. Other pre-clinical studies have indicated that a high fat diet (HFD), as a surrogate for an energy rich and calorie dense Western diet, results in strong stimulation of murine FGF23 via inflammatory pathways, specifically TNF $\alpha$ formation (184). Correspondingly, Klotho deficiency in mice has been shown to accelerate and exacerbate HFD-induced arterial stiffening and hypertension, via down-regulation of vascular $\mathrm{AMPK} \alpha$ expression, and activity (185). Yoshikawa et al. have also shown an age-related decrease in renal $\alpha$-Klotho expression in mice, itself negatively associated with the vitamin D level response to a high phosphate diet (177).

Secondary analysis of the placebo-controlled Styrian Vitamin D Hypertension trial (186) trial in 181 adults with arterial hypertension and a low serum concentration of $25(\mathrm{OH}) \mathrm{D}(<30 \mathrm{ng} / \mathrm{mL})$ has indicated that while vitamin $\mathrm{D}$ supplementation (2,800 IU daily) had no effect on FGF23 levels in the overall cohort, it did have an effect in subgroups with a baseline below $20 \mathrm{nl} / \mathrm{L}$. The authors proposed that this notable rise in FGF23 levels in the low baseline subgroup could be explained by pronounced elevation of calcitriol levels and concomitant increased intestinal phosphate absorption. Systematic reviewing by Charoenngam et al. (187) has highlighted that the evidence supporting an impact of Vitamin D on FGF23 is strongest when studies measure intact FGF23 (instead of c-terminal FGF23) with a pooled standardized mean difference (SMD) of 0.36 (95\%CI, 0.14, 0.57; $p=0.001 ; I^{2}$ of $36 \%)$ in vitamin D deficient individuals.

In a small sample of middle-aged sedentary adults $(n=$ 74) enrolled in the FIT-AGEING study, a negative association has been demonstrated between total alcoholic intake and SKlotho plasma levels $\left(\beta=-17.031 ; R^{2}=0.096, P=0.013\right)$, even when adjusted for body composition parameters (188). Pre-clinical models have suggested a role for dietary bio-actives in Klotho expression. Specifically, Hsu et al. suggest that this can be achieved with resveratrol administration in vitro (NRK$52 \mathrm{E}$ cells) and in vivo (mouse kidney) with involvement of the ATF3/c-Jun pathway (189). However, subsequent analysis in the FIT-AGEING cohort was only able to show a weak association between the Dietary Inflammatory Index (DII) (190) or adherence to the Mediterranean Diet (191) with soluble Klotho. These associations disappeared when corrected for Lean Mass Index. Of particular interest is the role of dietary fiber in the prevention of renal function decline in CKD patients. With a low fruit and vegetable intake, fiber, and polyphenolic intake is typically reduced, which could have a direct impact on the functionality of the gut microbiota. In a randomized control trial in 52 patients with CKD (stages 3-5), supplementation with $50 \mathrm{~g}$ oats daily (rich in the soluble fiber beta-glucan and polyphenolics) for 8 weeks, did have a beneficial impact on serum potassium, but not Klotho levels or parathyroid hormone (192). There is a lack of high quality trials with well-defined inflammatory, iron and vitamin $\mathrm{D}$ status focusing on dietary bioactive intake administrated in food or supplemental forms, and new evidence in this field will facilitate improved dietary guidance for kidney health and healthy aging.

\section{The Gut Microbiota}

The gut microbiota has emerged as a significant contributory factor to age related health [reviewed in (35)], where it appears to have a significant effect on the epigenetic landscape of aging. An understanding of any relationship between the gut microbiota and Klotho remains embryonic. However, there is an emerging indirect linkage based on the modulation of cell stress responses via processing of dietary acquired (poly)phenolic acids, which are potent Nrf2 agonists (193). The relationship between the microbiota and Nrf2 expression is an emerging therapeutic axis for a range treatment of the diseasome of aging and thus pertinent to Klotho. The transcription factor Nrf 2 controls a battery of over 390 cytoprotective genes and its expression is diminished with increasing age. Numerous nutritional intervention strategies are already in trial to enhance its age-related expression [reviewed in $(32,194)$ ]. Furthermore, pre-clinical studies are supportive on such an approach to tackle CKD, via indirect up-regulation of Klotho achieved via Nrf2 agonism. Indeed, use of a synthetic Nrf2 agonist has already been demonstrated to induce Klotho expression and mitigate the effects of CKD in mice. Klotho per se (i.e., direct Klotho agonism) has not featured as a mediator of such effects, though this is intuitive with respect to $\beta$-Klotho, as its FGF19 substrate is secreted by bile acids produced by gut microbiota (5). 
There is also an emerging relationship between the gut microbiota and the vitamin D/FGF23 axis. In murine models, Bora et al. (195) have demonstrated that antibiotic treatment increased vitamin D status, which in turn increased FGF23 levels after 14 days. However, the treatment effect on vitamin $\mathrm{D}$ was partly independent from the microbiota (as shown in GF mice) and potentially indicative of a direct impact on absorption.

\section{CONCLUSIONS}

The emerging field of Geroscience seeks to address the cellular and molecular mechanisms underpinning the aging process and to understand how, when and why these become dysregulated, as the diseasome of aging manifests. Modulation of Klotho has emerged as a prime target for interventions within this space, having the potential to complement and synergise with other emerging therapies, including senolytics and live biotherapeutics, as well as more conventional pharmaceuticals. The ability to couple any emerging therapies with nutritional and exercise based approaches, offers a more holistic means of translating these to the general population and thus improving healthspan. Applications to age related diseases, such as CKD are exciting, and have already demonstrated clinical benefit with more promised to come.

\section{REFERENCES}

1. Kuro-o M, Matsumura Y, Aizawa H, Kawaguchi H, Suga T, Utsugi T, et al. Mutation of the mouse klotho gene leads to a syndrome resembling ageing. Nature. (1997) 390:45-51. doi: 10.1038/36285

2. Shimada T, Kakitani M, Yamazaki Y, Hasegawa H, Takeuchi Y, Fujita T, et al. Targeted ablation of Fgf23 demonstrates an essential physiological role of FGF23 in phosphate and vitamin D metabolism. J Clin Invest. (2004) 113:561-8. doi: 10.1172/JCI200419081

3. Hu MC, Shiizaki K, Kuro-o M, Moe OW. Fibroblast growth factor 23 and Klotho: physiology and pathophysiology of an endocrine network of mineral metabolism. Annu Rev Physiol. (2013) 75:503-33. doi: 10.1146/annurev-physiol-030212-183727

4. Kuro-o M, Moe OW. FGF23- $\alpha$ Klotho as a paradigm for a kidney-bone network. Bone. (2017) 100:4-18. doi: 10.1016/j.bone.2016.11.013

5. Kuro-o M. The Klotho proteins in health and disease. Nat Rev Nephrol. (2019) 15:27-44. doi: 10.1038/s41581-018-0078-3

6. Ito S, Fujimori T, Hayashizaki Y, Nabeshima Y. Identification of a novel mouse membrane-bound family 1 glycosidase-like protein, which carries an atypical active site structure. Biochim Biophys Acta BBA Gene Struct Expr. (2002) 1576:341-5. doi: 10.1016/S0167-4781(02)00281-6

7. Ito S, Kinoshita S, Shiraishi N, Nakagawa S, Sekine S, Fujimori T, et al. Molecular cloning and expression analyses of mouse $\beta$ klotho, which encodes a novel Klotho family protein. Mech Dev. (2000) 98:1159. doi: 10.1016/S0925-4773(00)00439-1

8. Zou D, Wu W, He Y, Ma S, Gao J. The role of Klotho in chronic kidney disease. BMC Nephrol. (2018) 19:285. doi: 10.1186/s12882-018-1094-z

9. Matsumura Y, Aizawa H, Shiraki-Iida T, Nagai R, Kuro-o M, Nabeshima Y. Identification of the humanklothogene and its two transcripts encoding membrane and secretedklothoProtein. Biochem Biophys Res Commun. (1998) 242:626-30. doi: 10.1006/bbrc.1997.8019

10. Hu MC, Shi M, Gillings N, Flores B, Takahashi M, Kuro-O M, et al. Recombinant $\alpha$-Klotho may be prophylactic and therapeutic for acute to chronic kidney disease progression and uremic cardiomyopathy. Kidney Int. (2017) 91:1104-14. doi: 10.1016/j.kint.2016.10.034

\section{AUTHOR CONTRIBUTIONS}

All authors contributed to formulation, writing, discussion, and editing of the manuscript.

\section{FUNDING}

PS was supported by the Swedish Heart and Lung Foundation (No. 20160384), as well as the Strategic Research Programme in Diabetes at Karolinska Institutet (Swedish Research Council Grant No. 2009-1068). PS was supported by independent Ph.D. Partnership awards between the University of Glasgow and Constant Pharma Ltd. and 4D Pharma limited. These awards are to investigate novel therapeutics and microbiota differences in aging. None involve directly investigating Klotho. The funders had no role in study design, data collection, and analysis, decision to publish, or preparation of the manuscript.

\section{ACKNOWLEDGMENTS}

The authors would like to give special thanks to Ognian Neytchev for help with referencing the manuscript. Some of the graphical items in the figures were designed with Biorender.com.

11. Kurosu H. Suppression of aging in mice by the hormone Klotho. Science. (2005) 309:1829-33. doi: 10.1126/science.1112766

12. Imura A, Iwano A, Tohyama O, Tsuji Y, Nozaki K, Hashimoto N, et al. Secreted Klotho protein in sera and CSF: implication for post-translational cleavage in release of Klotho protein from cell membrane. FEBS Lett. (2004) 565:143-7. doi: 10.1016/j.febslet.2004.03.090

13. Akimoto T, Yoshizawa H, Watanabe Y, Numata A, Yamazaki T, Takeshima E, et al. Characteristics of urinary and serum soluble Klotho protein in patients with different degrees of chronic kidney disease. BMC Nephrol. (2012) 13:155. doi: 10.1186/1471-2369-13-155

14. Semba RD, Moghekar AR, Hu J, Sun K, Turner R, Ferrucci L, et al. Klotho in the cerebrospinal fluid of adults with and without Alzheimer's disease. Neurosci Lett. (2014) 558:37-40. doi: 10.1016/j.neulet.2013. 10.058

15. Shimada $T$, Hasegawa $H$, Yamazaki $Y$, Muto $T$, Hino $R$, Takeuchi Y, et al. FGF-23 is a potent regulator of Vitamin D metabolism and phosphate homeostasis. J Bone Miner Res. (2003) 19:429-35. doi: 10.1359/JBMR.0301264

16. Chen G, Liu Y, Goetz R, Fu L, Jayaraman S, Hu M-C, et al. $\alpha$-Klotho is a nonenzymatic molecular scaffold for FGF23 hormone signalling. Nature. (2018) 553:461-6. doi: 10.1038/nature25451

17. Kurosu H, Ogawa Y, Miyoshi M, Yamamoto M, Nandi A, Rosenblatt KP, et al. Regulation of fibroblast growth factor-23 signaling by Klotho. J Biol Chem. (2006) 281:6120-3. doi: 10.1074/jbc.C500457200

18. Lindberg K, Amin R, Moe OW, Hu M-C, Erben RG, Östman Wernerson A, et al. The kidney is the principal organ mediating Klotho effects. J Am Soc Nephrol. (2014) 25:2169-75. doi: 10.1681/ASN.2013111209

19. Shi M, Flores B, Gillings N, Bian A, Cho HJ, Yan S, et al. $\alpha$ Klotho mitigates progression of AKI to CKD through activation of autophagy. J Am Soc Nephrol. (2016) 27:2331-45. doi: 10.1681/ASN.2015060613

20. Neyra JA, Hu MC. Potential application of Klotho in human chronic kidney disease. Bone. (2017) 100:41-9. doi: 10.1016/j.bone.2017.01.017

21. Zhu L, Stein LR, Kim D, Ho K, Yu G-Q, Zhan L, et al. Klotho controls the brain-immune system interface in the choroid plexus. Proc Natl Acad Sci USA. (2018) 115:E11388-96. doi: 10.1073/pnas.1808609115 
22. Quarles LD. Fibroblast growth factor 23 and $\alpha$-Klotho co-dependent and independent functions. Curr Opin Nephrol Hypertens. (2019) 28:1625. doi: 10.1097/MNH.0000000000000467

23. Richter B, Faul C. FGF23 actions on target tissues-with and without Klotho. Front Endocrinol. (2018) 9:189. doi: 10.3389/fendo.2018.00189

24. $\mathrm{Li} \mathrm{S}, \mathrm{Yu} \mathrm{L}, \mathrm{He} \mathrm{A}$, Liu Q. Klotho inhibits unilateral ureteral obstruction-induced endothelial-to-mesenchymal transition via TGF-B1/Smad2/Snail1 signaling in mice. Front Pharmacol. (2019) 10:348. doi: 10.3389/fphar.2019.00348

25. Iurciuc S, Cimpean AM, Mitu F, Heredea R, Iurciuc M. Vascular aging and subclinical atherosclerosis: why such a "never ending" and challenging story in cardiology? Clin Interv Aging. (2017) 12:133945. doi: 10.2147/CIA.S141265

26. Mencke R, Hillebrands J-L. The role of the anti-ageing protein Klotho in vascular physiology and pathophysiology. Ageing Res Rev. (2017) 35:12446. doi: 10.1016/j.arr.2016.09.001

27. Lau WL, Leaf EM, Hu MC, Takeno MM, Kuro-o M, Moe OW, et al. Vitamin $\mathrm{D}$ receptor agonists increase Klotho and osteopontin while decreasing aortic calcification in mice with chronic kidney disease fed a high phosphate diet. Kidney Int. (2012) 82:1261-70. doi: 10.1038/ki.2012.322

28. Fulop T, Larbi A, Witkowski JM, McElhaney J, Loeb M, Mitnitski A, et al. Aging, frailty and age-related diseases. Biogerontology. (2010) 11:54763. doi: 10.1007/s10522-010-9287-2

29. Shiels PG, McGuinness D, Eriksson M, Kooman JP, Stenvinkel P. The role of epigenetics in renal ageing. Nat Rev Nephrol. (2017) 13:47182. doi: 10.1038/nrneph.2017.78

30. Shiels PG, Stenvinkel P, Kooman JP, McGuinness D. Circulating markers of ageing and allostatic load: a slow train coming. Pract Lab Med. (2016) 7:49-54. doi: 10.1016/j.plabm.2016.04.002

31. Bitto A, Wang AM, Bennett CF, Kaeberlein M. Biochemical genetic pathways that modulate aging in multiple species: figure 1. Cold Spring Harb Perspect Med. (2015) 5:a025114. doi: 10.1101/cshperspect.a025114

32. Stenvinkel P, Painer J, Kuro-o M, Lanaspa M, Arnold W, Ruf T, et al. Novel treatment strategies for chronic kidney disease: insights from the animal kingdom. Nat Rev Nephrol. (2018) 14:265-84. doi: 10.1038/nrneph.2017.169

33. López-Otín C, Blasco MA, Partridge L, Serrano M, Kroemer G. The hallmarks of aging. Cell. (2013) 153:1194-217. doi: 10.1016/j.cell.2013.05.039

34. Shiels PG, Buchanan S, Selman C, Stenvinkel P. Allostatic load and ageing: linking the microbiome and nutrition with age-related health. Biochem Soc Trans. (2019) 47:1165-72. doi: 10.1042/BST20190110

35. O'Toole PW, Shiels PG. The role of the microbiota in sedentary lifestyle disorders and ageing: lessons from the animal kingdom. J Intern Med. (2020) Mar;287:271-82. doi: 10.1111/joim.13021

36. Kuro-o M. A potential link between phosphate and agingLessons from Klotho-deficient mice. Mech Ageing Dev. (2010) 131:270-5. doi: 10.1016/j.mad.2010.02.008

37. Kuro-o M. Phosphate and Klotho. Kidney Int. (2011) 79:S203. doi: $10.1038 / \mathrm{ki} .2011 .26$

38. Erben RG, Andrukhova O. FGF23-Klotho signaling axis in the kidney. Bone. (2017) 100:62-8. doi: 10.1016/j.bone.2016.09.010

39. Martin A, David V, Quarles LD. Regulation and function of the FGF23/Klotho endocrine pathways. Physiol Rev. (2012) 92:131-55. doi: 10.1152/physrev.00002.2011

40. Grabner A, Amaral AP, Schramm K, Singh S, Sloan A, Yanucil $\mathrm{C}$, et al. Activation of cardiac fibroblast growth factor receptor 4 causes left ventricular hypertrophy. Cell Metab. (2015) 22:1020-32. doi: 10.1016/j.cmet.2015.09.002

41. Grabner A, Schramm K, Silswal N, Hendrix M, Yanucil C, Czaya B, et al. FGF23/FGFR4-mediated left ventricular hypertrophy is reversible. Sci Rep. (2017) 7:1993. doi: 10.1038/s41598-017-02068-6

42. Singh S, Grabner A, Yanucil C, Schramm K, Czaya B, Krick S, et al. Fibroblast growth factor 23 directly targets hepatocytes to promote inflammation in chronic kidney disease. Kidney Int. (2016) 90:98596. doi: 10.1016/j.kint.2016.05.019

43. Liu S, Vierthaler L, Tang W, Zhou J, Quarles LD. FGFR3 and FGFR4 do not mediate renal effects of FGF23. J Am Soc Nephrol. (2008) 19:234250. doi: 10.1681/ASN.2007121301
44. Ebert T, Pawelzik S-C, Witasp A, Arefin S, Hobson S, Kublickiene K, et al. Inflammation and premature ageing in chronic kidney disease. Toxins. (2020) 12:227. doi: 10.3390/toxins12040227

45. Andrukhova O, Zeitz U, Goetz R, Mohammadi M, Lanske B, Erben RG. FGF23 acts directly on renal proximal tubules to induce phosphaturia through activation of the ERK1/2-SGK1 signaling pathway. Bone. (2012) 51:621-8. doi: 10.1016/j.bone.2012.05.015

46. Ben-Dov IZ, Galitzer H, Lavi-Moshayoff V, Goetz R, Kuro-o M, Mohammadi $\mathrm{M}$, et al. The parathyroid is a target organ for FGF23 in rats. J Clin Invest. (2007) 117:4003-8. doi: 10.1172/JCI32409

47. Liu S, Tang W, Zhou J, Stubbs JR, Luo Q, Pi M, et al. Fibroblast growth factor 23 is a counter-regulatory phosphaturic hormone for vitamin D. J Am Soc Nephrol. (2006) 17:1305-15. doi: 10.1681/ASN.2005111185

48. Inoue Y, Segawa H, Kaneko I, Yamanaka S, Kusano K, Kawakami E, et al. Role of the vitamin D receptor in FGF23 action on phosphate metabolism. Biochem J. (2005) 390:325-31. doi: 10.1042/BJ20041799

49. Rhee Y, Bivi N, Farrow E, Lezcano V, Plotkin LI, White KE, et al. Parathyroid hormone receptor signaling in osteocytes increases the expression of fibroblast growth factor-23 in vitro and in vivo. Bone. (2011) 49:63643. doi: 10.1016/j.bone.2011.06.025

50. Quinn SJ, Thomsen ARB, Pang JL, Kantham L, Bräuner-Osborne H, Pollak $\mathrm{M}$, et al. Interactions between calcium and phosphorus in the regulation of the production of fibroblast growth factor 23 in vivo. Am J Physiol-Endocrinol Metab. (2013) 304:E310-20. doi: 10.1152/ajpendo.00460.2012

51. Rodriguez-Ortiz ME, Lopez I, Muñoz-Castañeda JR, Martinez-Moreno JM, Ramírez AP, Pineda C, et al. Calcium deficiency reduces circulating levels of FGF23. J Am Soc Nephrol. (2012) 23:1190-7. doi: 10.1681/ASN.2011101006

52. Shanahan CM. Mechanisms of vascular calcification in CKDevidence for premature ageing? Nat Rev Nephrol. (2013) 9:661-670. doi: 10.1038/nrneph.2013.176

53. Hu MC, Kuro-o M, Moe OW. Klotho and chronic kidney disease. In Razzaque MS, editor. Contributions to Nephrology. Basel: S. Karger AG (2013). p. 47-63. Available online at: https://www.karger.com/Article/ FullText/346778 (accessed June 9, 2020).

54. Giachelli CM. The emerging role of phosphate in vascular calcification. Kidney Int. (2009) 75:890-7. doi: 10.1038/ki.2008.644

55. Hu MC, Shi M, Zhang J, Quiñones H, Griffith C, Kuro-o M, et al. Klotho deficiency causes vascular calcification in chronic kidney disease. J Am Soc Nephrol. (2011) 22:124-36. doi: 10.1681/ASN.2009121311

56. Hill NR, Fatoba ST, Oke JL, Hirst JA, O'Callaghan CA, Lasserson DS, et al. Global prevalence of chronic kidney disease - a systematic review and metaanalysis. PLoS ONE. (2016) 11:e0158765. doi: 10.1371/journal.pone.0158765

57. Luyckx VA, Cherney DZI, Bello AK. Preventing CKD in developed countries. Kidney Int Rep. (2020) 5:263-77. doi: 10.1016/j.ekir.2019.12.003

58. Kooman JP, Kotanko P, Schols AMWJ, Shiels PG, Stenvinkel P. Chronic kidney disease and premature ageing. Nat Rev Nephrol. (2014) 10:73242. doi: 10.1038/nrneph.2014.185

59. Carracedo M, Artiach G, Witasp A, Clària J, Carlström M, LagunaFernandez A, et al. The G-protein coupled receptor ChemR23 determines smooth muscle cell phenotypic switching to enhance high phosphate-induced vascular calcification. Cardiovasc Res. (2019) 115:1557-66. doi: 10.1093/cvr/cvy316

60. Abbasian N, Burton JO, Herbert KE, Tregunna B-E, Brown JR, GhaderiNajafabadi M, et al. Hyperphosphatemia, phosphoprotein phosphatases, and microparticle release in vascular endothelial cells. J Am Soc Nephrol. (2015) 26:2152-62. doi: 10.1681/ASN.2014070642

61. Voelkl J, Tuffaha R, Luong TTD, Zickler D, Masyout J, Feger M, et al. Zinc inhibits phosphate-induced vascular calcification through TNFAIP3mediated suppression of NF- $\kappa$ B. J Am Soc Nephrol. (2018) 29:163648. doi: 10.1681/ASN.2017050492

62. Glorieux G, Gryp T, Perna A. Gut-derived metabolites and their role in immune dysfunction in chronic kidney disease. Toxins. (2020) 12:245. doi: 10.3390/toxins12040245

63. Hobson S, Arefin S, Kublickiene K, Shiels P, Stenvinkel P. Senescent cells in early vascular ageing and bone disease of chronic kidney disease-a novel target for treatment. Toxins. (2019) 11:82. doi: 10.3390/toxins110 20082 
64. Kooman JP, Dekker MJ, Usvyat LA, Kotanko P, van der Sande FM, Schalkwijk CG, et al. Inflammation and premature aging in advanced chronic kidney disease. Am J Physiol-Ren Physiol. (2017) 313:F93850. doi: 10.1152/ajprenal.00256.2017

65. Franceschi C, Garagnani P, Parini P, Giuliani C, Santoro A. Inflammaging: a new immune-metabolic viewpoint for age-related diseases. Nat Rev Endocrinol. (2018) 14:576-90. doi: 10.1038/s41574-018-0059-4

66. Goligorsky MS. Chronic kidney disease. Am J Pathol. (2020) 190:116471. doi: 10.1016/j.ajpath.2020.01.016

67. Taniguchi K, Karin M. NF-kB, inflammation, immunity and cancer: coming of age. Nat Rev Immunol. (2018) 18:309-24. doi: 10.1038/nri.2017.142

68. Osorio FG, Soria-Valles C, Santiago-Fernández O, Freije JMP, López-Otín C. NF- $\mathrm{KB}$ signaling as a driver of ageing. In International Review of Cell and Molecular Biology. Elsevier (2016) p. 133-74. Available online at: https:// linkinghub.elsevier.com/retrieve/pii/S1937644816300351 (accessed June 9, 2020).

69. Costantino S, Paneni F, Cosentino F. Ageing, metabolism and cardiovascular disease: mechanisms of cardiovascular ageing. J Physiol. (2016) 594:206173. doi: $10.1113 / \mathrm{JP} 270538$

70. Kang C, Xu Q, Martin TD, Li MZ, Demaria M, Aron L, et al. The DNA damage response induces inflammation and senescence by inhibiting autophagy of GATA4. Science. (2015) 349:aaa5612. doi: 10.1126/science.aaa5612

71. Carracedo J, Alique M, Vida C, Bodega G, Ceprián N, Morales E, et al. Mechanisms of cardiovascular disorders in patients with chronic kidney disease: a process related to accelerated senescence. Front Cell Dev Biol. (2020) 8:185. doi: 10.3389/fcell.2020.00185

72. Arefin S, Buchanan S, Hobson S, Steinmetz J, Alsalhi S, Shiels PG, et al. Nrf2 in early vascular ageing: calcification, senescence and therapy. Clin Chim Acta. (2020) 505:108-18. doi: 10.1016/j.cca.2020.02.026

73. Ramezani A, Raj DS. The gut microbiome, kidney disease, and targeted interventions. J Am Soc Nephrol. (2014) 25:65770. doi: 10.1681/ASN.2013080905

74. Sirich TL, Funk BA, Plummer NS, Hostetter TH, Meyer TW. Prominent accumulation in hemodialysis patients of solutes normally cleared by tubular secretion. J Am Soc Nephrol. (2014) 25:615-22. doi: 10.1681/ASN.2013060597

75. Muteliefu G, Shimizu H, Enomoto A, Nishijima F, Takahashi M, Niwa T. Indoxyl sulfate promotes vascular smooth muscle cell senescence with upregulation of p53, p21, and prelamin A through oxidative stress. Am J Physiol Cell Physiol. (2012) 303:C126-34. doi: 10.1152/ajpcell.00329.2011

76. Chaudhuri J, Bains Y, Guha S, Kahn A, Hall D, Bose N, et al. The role of advanced glycation end products in aging and metabolic diseases: bridging association and causality. Cell Metab. (2018) 28:33752. doi: 10.1016/j.cmet.2018.08.014

77. Stinghen AEM, Massy ZA, Vlassara H, Striker GE, Boullier A. Uremic toxicity of advanced glycation end products in CKD. J Am Soc Nephrol. (2016) 27:354-70. doi: 10.1681/ASN.2014101047

78. Liu WJ, Shen TT, Chen RH, Wu H-L, Wang YJ, Deng JK, et al. Autophagylysosome pathway in renal tubular epithelial cells is disrupted by advanced glycation end products in diabetic nephropathy. J Biol Chem. (2015) 290:20499-510. doi: 10.1074/jbc.M115.666354

79. Shi $M$, Yang $S$, Zhu $X$, Sun $D$, Sun $D$, Jiang $X$, et al. The RAGE/STAT5/autophagy axis regulates senescence in mesangial cells. Cell Signal. (2019) 62:109334. doi: 10.1016/j.cellsig.2019.05.019

80. Carrero JJ, Stenvinkel P, Fellström B, Qureshi AR, Lamb K, Heimbürger O, et al. Telomere attrition is associated with inflammation, low fetuin-A levels and high mortality in prevalent haemodialysis patients. J Intern Med. (2008) 263:302-12. doi: 10.1111/j.1365-2796.2007.01890.x

81. Morii K, Yamasaki S, Doi S, Irifuku T, Sasaki K, Doi T, et al. MicroRNA200c regulates KLOTHO expression in human kidney cells under oxidative stress. PLoS ONE. (2019) 14:e0218468. doi: 10.1371/journal.pone.02 18468

82. Yin S, Zhang Q, Yang J, Lin W, Li Y, Chen F, et al. TGF $\beta$ incurred epigenetic aberrations of miRNA and DNA methyltransferase suppress Klotho and potentiate renal fibrosis. Biochim Biophys Acta BBA Mol Cell Res. (2017) 1864:1207-16. doi: 10.1016/j.bbamcr.2017. 03.002
83. Zoccali C, Vanholder R, Massy ZA, Ortiz A, Sarafidis P, et al. The systemic nature of CKD. Nat Rev Nephrol. (2017) 13:344-58. doi: 10.1038/nrneph.2017.52

84. Shimada T, Takeshita Y, Murohara T, Sasaki K, Egami K, Shintani S, et al. Angiogenesis and vasculogenesis are impaired in the precocious-aging klotho mouse. Circulation. (2004) 110:1148-55. doi: 10.1161/01.CIR.0000139854.74847.99

85. Fernandez-Fernandez B, Izquierdo MC, Valiño-Rivas L, Nastou D, Sanz AB, Ortiz A, et al. Albumin downregulates Klotho in tubular cells. Nephrol Dial Transplant. (2018) 33:1712-22. doi: 10.1093/ndt/ gfx376

86. Moreno JA, Izquierdo MC, Sanchez-Niño MD, Suárez-Alvarez B, Lopez-Larrea C, Jakubowski A, et al. The inflammatory cytokines TWEAK and TNF $\alpha$ reduce renal klotho expression through NFKB. J Am Soc Nephrol. (2011) 22:1315-25. doi: 10.1681/ASN.20101 01073

87. Thurston RD, Larmonier CB, Majewski PM, Ramalingam R, MiduraKiela M, Laubitz D, et al. Tumor necrosis factor and interferon- $\gamma$ downregulate Klotho in mice with colitis. Gastroenterology. (2010) 138:138494.e2. doi: 10.1053 /j.gastro.2009.12.002

88. Sanchez-Niño MD, Fernandez-Fernandez B, Ortiz A. Klotho, the elusive kidney-derived anti-ageing factor. Clin Kidney J. (2020) 13:125-7. doi: 10.1093/ckj/sfz125

89. Ide N, Olauson H, Sato T, Densmore MJ, Wang H, Hanai J, et al. In vivo evidence for a limited role of proximal tubular Klotho in renal phosphate handling. Kidney Int. (2016) 90:348-62. doi: 10.1016/j.kint.2016.04.009

90. Hruska KA, Lanske B, Moe OW. Crosstalk between kidney and bone - bench to bedside. Bone. (2017) 100:1-3. doi: 10.1016/j.bone.2017.03.046

91. Razzaque MS. The FGF23-Klotho axis: endocrine regulation of phosphate homeostasis. Nat Rev Endocrinol. (2009) 5:6119. doi: 10.1038/nrendo.2009.196

92. Desjardins L, Liabeuf S, Renard C, Lenglet A, Lemke H-D, Choukroun G, et al. FGF23 is independently associated with vascular calcification but not bone mineral density in patients at various CKD stages. Osteoporos Int. (2012) 23:2017-25. doi: 10.1007/s00198-011-1838-0

93. Smith ER, Holt SG, Hewitson TD. $\alpha$ Klotho-FGF23 interactions and their role in kidney disease: a molecular insight. Cell Mol Life Sci. (2019) 76:470524. doi: 10.1007/s00018-019-03241-y

94. Kuro-o M. Klotho and endocrine fibroblast growth factors: markers of chronic kidney disease progression and cardiovascular complications? Nephrol Dial Transplant. (2019) 34:15-21. doi: 10.1093/ndt/gfy126

95. Tanaka S, Okusa MD. Crosstalk between the nervous system and the kidney. Kidney Int. (2020) 97:466-76. doi: 10.1016/j.kint.2019.10.032

96. Chen C-D, Sloane JA, Li H, Aytan N, Giannaris EL, Zeldich E, et al. The antiaging protein Klotho enhances oligodendrocyte maturation and myelination of the CNS. J Neurosci. (2013) 33:1927-39. doi: 10.1523/JNEUROSCI.2080-12.2013

97. Viggiano D, Wagner CA, Martino G, Nedergaard M, Zoccali C, Unwin R, et al. Mechanisms of cognitive dysfunction in CKD. Nat Rev Nephrol. (2020) 16:452-69. doi: 10.1038/s41581-020-0266-9

98. Bobot M, Thomas L, Moyon A, Fernandez S, McKay N, Balasse L, et al. Uremic toxic blood-brain barrier disruption mediated by AhR activation leads to cognitive impairment during experimental renal dysfunction. J Am Soc Nephrol. (2020) 31:1509-21. doi: 10.1681/ASN.20190 70728

99. Zhou X, Chen K, Lei H, Sun Z. Klotho gene deficiency causes saltsensitive hypertension via monocyte chemotactic protein-1/CC chemokine receptor 2-mediated inflammation. J Am Soc Nephrol. (2015) 26:12132. doi: 10.1681/ASN.2013101033

100. Citterio L, Delli Carpini S, Lupoli S, Brioni E, Simonini M, Fontana S, et al. Klotho gene in human salt-sensitive hypertension. Clin J Am Soc Nephrol. (2020) 15:375-83. doi: 10.2215/CJN.08620719

101. Sun C-Y, Chang S-C, Wu M-S. Suppression of Klotho expression by proteinbound uremic toxins is associated with increased DNA methyltransferase expression and DNA hypermethylation. Kidney Int. (2012) 81:64050. doi: $10.1038 /$ ki.2011.445

102. Buendía P, Ramírez R, Aljama P, Carracedo J. Klotho prevents translocation of NFkB. In: Vitam Horm. (2016) 101:119-50. doi: 10.1016/bs.vh.2016.02.005 
103. Maekawa Y, Ishikawa K, Yasuda O, Oguro R, Hanasaki H, Kida I, et al. Klotho suppresses TNF- $\alpha$-induced expression of adhesion molecules in the endothelium and attenuates NF- $\mathrm{KB}$ activation. Endocrine. (2009) 35:3416. doi: 10.1007/s12020-009-9181-3

104. Fujihara CK, Antunes GR, Mattar AL, Malheiros DMAC, Vieira JM, Zatz R. Chronic inhibition of nuclear factor- $\kappa \mathrm{B}$ attenuates renal injury in the 5/6 renal ablation model. Am J Physiol-Ren Physiol. (2007) 292:F929. doi: 10.1152/ajprenal.00184.2006

105. Ding X, Wang X, Xue W, Tian X, Li Y, Jiao F, et al. Blockade of the nuclear factor Kappa $B$ pathway prolonged islet allograft survival: blockade of the NF-KB pathway. Artif Organs. (2012) 36:E21-7. doi: 10.1111/j.1525-1594.2011.01395.x

106. Volpini RA, Costa RS, da Silva CGA, Coimbra TM. Inhibition of nuclear factor- $\kappa \mathrm{B}$ activation attenuates tubulointerstitial nephritis induced by gentamicin. Nephron Physiol. (2004) 98:97-106. doi: 10.1159/000081558

107. Zhao Y, Banerjee S, Dey N, LeJeune WS, Sarkar PS, Brobey R, et al. Klotho depletion contributes to increased inflammation in kidney of the $\mathrm{db} / \mathrm{db}$ mouse model of diabetes via RelA (Serine)536 phosphorylation. Diabetes. (2011) 60:1907-16. doi: 10.2337/db10-1262

108. Vervloet MG, Adema AY, Larsson TE, Massy ZA. The role of Klotho on vascular calcification and endothelial function in chronic kidney disease. Semin Nephrol. (2014) 34:578-85. doi: 10.1016/j.semnephrol.2014.09.003

109. Temmar M, Liabeuf S, Renard C, Czernichow S, Esper NE, Shahapuni I, et al. Pulse wave velocity and vascular calcification at different stages of chronic kidney disease. J Hypertens. (2010) 28:163-9. doi: 10.1097/HJH.0b013e328331b81e

110. Leifheit-Nestler M, Richter B, Basaran M, Nespor J, Vogt I, Alesutan I, et al. Impact of altered mineral metabolism on pathological cardiac remodeling in elevated fibroblast growth factor 23. Front Endocrinol. (2018) 9:333. doi: 10.3389 /fendo.2018.00333

111. Zhao Y, Zhao M-M, Cai Y, Zheng M-F, Sun W-L, Zhang S-Y, et al. Mammalian target of rapamycin signaling inhibition ameliorates vascular calcification via Klotho upregulation. Kidney Int. (2015) 88:71121. doi: 10.1038/ki.2015.160

112. Hamano T. Klotho upregulation by rapamycin protects against vascular disease in CKD. Kidney Int. (2015) 88:660-2. doi: 10.1038/ki.2015.223

113. Hum JM, O'Bryan LM, Tatiparthi AK, Cass TA, Clinkenbeard EL, Cramer MS, et al. Chronic hyperphosphatemia and vascular calcification are reduced by stable delivery of soluble Klotho. J Am Soc Nephrol. (2017) 28:116274. doi: 10.1681/ASN.2015111266

114. Masuda H, Chikuda H, Suga T, Kawaguchi H, Kuro-o M. Regulation of multiple ageing-like phenotypes by inducible Klotho gene expression in Klotho mutant mice. Mech Ageing Dev. (2005) 126:1274-83. doi: 10.1016/j.mad.2005.07.007

115. Lin HY-H, Lee Y-L, Lin K-D, Chiu Y-W, Shin S-J, Hwang S-J, et al. Association of renal elasticity and renal function progression in patients with chronic kidney disease evaluated by real-time ultrasound elastography. Sci Rep. (2017) 7:43303. doi: 10.1038/srep43303

116. Zhang H, Nair V, Saha J, Atkins KB, Hodgin JB, Saunders TL, et al. Podocyte-specific JAK2 overexpression worsens diabetic kidney disease in mice. Kidney Int. (2017) 92:909-21. doi: 10.1016/j.kint.2017. 03.027

117. Webster AC, Nagler EV, Morton RL, Masson P. Chronic idney disease. Lancet. (2017) 389:1238-52. doi: 10.1016/S0140-6736(16)32064-5

118. Sugiura H, Yoshida T, Shiohira S, Kohei J, Mitobe M, Kurosu $\mathrm{H}$, et al. Reduced Klotho expression level in kidney aggravates renal interstitial fibrosis. Am J Physiol-Ren Physiol. (2012) 302:F1252-64. doi: 10.1152/ajprenal.00294.2011

119. Guan T, Gao B, Chen G, Chen X, Janssen M, Uttarwar L, et al. Colchicine attenuates renal injury in a model of hypertensive chronic kidney disease. Am J Physiol-Ren Physiol. (2013) 305:F146676. doi: 10.1152/ajprenal.00057.2013

120. Doi S, Zou Y, Togao O, Pastor JV, John GB, Wang L, et al. Klotho inhibits transforming growth factor- $\beta 1$ (TGF- $\beta 1$ ) signaling and suppresses renal fibrosis and cancer metastasis in mice. J Biol Chem. (2011) 286:865565. doi: 10.1074/jbc.M110.174037
121. Guan X, Nie L, He T, Yang K, Xiao T, Wang S, et al. Klotho suppresses renal tubulo-interstitial fibrosis by controlling basic fibroblast growth factor2 signalling: Klotho suppresses FGF2-induced renal fibrosis. J Pathol. (2014) 234:560-72. doi: 10.1002/path.4420

122. Hu MC, Kuro-o M, Moe OW. Renal and extrarenal actions of Klotho. Semin Nephrol. (2013) 33:118-29. doi: 10.1016/j.semnephrol.2012.12.013

123. Eckardt K-U, Coresh J, Devuyst O, Johnson RJ, Köttgen A, Levey AS, et al. Evolving importance of kidney disease: from subspecialty to global health burden. Lancet. (2013) 382:158-69. doi: 10.1016/S0140-6736(13)60439-0

124. Chen T-H, Kuro-o M, Chen C-H, Sue Y-M, Chen Y-C, Wu H-H, et al. The secreted Klotho protein restores phosphate retention and suppresses accelerated aging in Klotho mutant mice. Eur J Pharmacol. (2013) 698:6773. doi: 10.1016/j.ejphar.2012.09.032

125. Hu MC, Kuro-o M, Moe OW. The emerging role of Klotho in clinical nephrology. Nephrol Dial Transplant. (2012) 27:26507. doi: $10.1093 / \mathrm{ndt} / \mathrm{gfs} 160$

126. Rotondi S, Pasquali M, Tartaglione L, Muci ML, Mandanici G, Leonangeli C, et al. Soluble $\alpha$-Klotho serum levels in chronic kidney disease. Int J Endocrinol. (2015) 2015:1-8. doi: 10.1155/2015/872193

127. Tan S-J, Smith ER, Holt SG, Hewitson TD, Toussaint ND. Soluble Klotho may be a marker of phosphate reabsorption. Clin Kidney J. (2017) 10:397404. doi: 10.1093/ckj/sfw146

128. Koh N, Fujimori T, Nishiguchi S, Tamori A, Shiomi S, Nakatani $\mathrm{T}$, et al. Severely reduced production of Klotho in human chronic renal failure kidney. Biochem Biophys Res Commun. (2001) 280:101520. doi: 10.1006/bbrc.2000.4226

129. Pavik I, Jaeger P, Ebner L, Wagner CA, Petzold K, Spichtig D, et al. Secreted Klotho and FGF23 in chronic kidney disease stage 1 to 5: a sequence suggested from a cross-sectional study. Nephrol Dial Transplant. (2013) 28:352-9. doi: 10.1093/ndt/gfs460

130. Fernández-Fernández B, Valiño-Rivas L, Sánchez-Niño MD, Ortiz A. Albuminuria downregulation of the anti-aging factor Klotho: the missing link potentially explaining the association of pathological albuminuria with premature death. Adv Ther. (2020) 37:62-72. doi: 10.1007/s12325-019-01180-5

131. Barker SL, Pastor J, Carranza D, Quiñones H, Griffith C, Goetz R, et al. The demonstration of $\alpha$ Klotho deficiency in human chronic kidney disease with a novel synthetic antibody. Nephrol Dial Transplant. (2015) 30:22333. doi: 10.1093/ndt/gfu291

132. Heijboer AC, Blankenstein MA, Hoenderop J, de Borst MH, Vervloet MG, on behalf of the NIGRAM consortium. Laboratory aspects of circulating -Klotho. Nephrol Dial Transplant. (2013) 28:2283-7. doi: 10.1093/ndt/gft236

133. Hu MC. Klotho connects intermedin1-53 to suppression of vascular calcification in chronic kidney disease. Kidney Int. (2016) 89:5347. doi: 10.1016/j.kint.2015.12.036

134. Takenaka T, Inoue T, Miyazaki T, Kobori H, Nishiyama A, Ishii N, et al. Klotho suppresses the renin-angiotensin system in adriamycin nephropathy. Nephrol Dial Transplant. (2016) 32:791-800. doi: 10.1093/ndt/gfw340

135. Hu M-C, Shi M, Zhang J, Quiñones H, Kuro-o M, Moe OW. Klotho deficiency is an early biomarker of renal ischemia-reperfusion injury and its replacement is protective. Kidney Int. (2010) 78:124051. doi: $10.1038 /$ ki.2010.328

136. Cheikhi A, Barchowsky A, Sahu A, Shinde SN, Pius A, Clemens ZJ, et al. Klotho: an elephant in aging research. J Gerontol Ser A. (2019) 74:103142. doi: 10.1093/gerona/glz061

137. Haruna Y, Kashihara N, Satoh M, Tomita N, Namikoshi T, Sasaki $\mathrm{T}$, et al. Amelioration of progressive renal injury by genetic manipulation of Klotho gene. Proc Natl Acad Sci USA. (2007) 104:2331-6. doi: 10.1073/pnas.0611079104

138. Qiao X, Rao P, Zhang Y, Liu L, Pang M, Wang H, et al. Redirecting TGF$\beta$ signaling through the $\beta$-Catenin/Foxo complex prevents kidney fibrosis. $J$ Am Soc Nephrol. (2018) 29:557-70. doi: 10.1681/ASN.2016121362

139. Chen J, Zhang X, Zhang H, Liu T, Zhang H, Teng J, et al. Indoxyl sulfate enhance the hypermethylation of Klotho and promote the process of vascular calcification in chronic kidney disease. Int J Biol Sci. (2016) 12:1236-46. doi: 10.7150/ijbs.15195 
140. Azuma M, Koyama D, Kikuchi J, Yoshizawa H, Thasinas D, Shiizaki K, et al. Promoter methylation confers kidney-specific expression of the Klotho gene. FASEB J. (2012) 26:4264-74. doi: 10.1096/fj.12-211631

141. Zhang H, Li Y, Fan Y, Wu J, Zhao B, Guan Y, et al. Klotho is a target gene of PPAR- $\gamma$. Kidney Int. (2008) 74:732-9. doi: 10.1038/ki.2008.244

142. Benigni A, Corna D, Zoja C, Sonzogni A, Latini R, Salio M, et al. Disruption of the Ang II type 1 receptor promotes longevity in mice. J Clin Invest. (2009) 119:524-30. doi: 10.1172/JCI36703

143. Yoon HE, Ghee JY, Piao S, Song J-H, Han DH, Kim S, et al. Angiotensin II blockade upregulates the expression of Klotho, the anti-ageing gene, in an experimental model of chronic cyclosporine nephropathy. Nephrol Dial Transplant. (2011) 26:800-13. doi: 10.1093/ndt/gfq537

144. Zhou Q, Lin S, Tang R, Veeraragoo P, Peng W, Wu R. Role of fosinopril and valsartan on Klotho gene expression induced by angiotensin ii in rat renal tubular epithelial cells. Kidney Blood Press Res. (2010) 33:18692. doi: $10.1159 / 000316703$

145. Forster RE, Jurutka PW, Hsieh J-C, Haussler CA, Lowmiller CL, Kaneko I, et al. Vitamin D receptor controls expression of the anti-aging Klotho gene in mouse and human renal cells. Biochem Biophys Res Commun. (2011) 414:557-62. doi: 10.1016/j.bbrc.2011.09.117

146. Ritter CS, Zhang S, Delmez J, Finch JL, Slatopolsky E. Differential expression and regulation of Klotho by paricalcitol in the kidney, parathyroid, and aorta of uremic rats. Kidney Int. (2015) 87:1141-52. doi: 10.1038/ki.2015.22

147. Chang JR, Guo J, Wang Y, Hou YL, Lu WW, Zhang JS, et al. Intermedin1-53 attenuates vascular calcification in rats with chronic kidney disease by upregulation of $\alpha$-Klotho. Kidney Int. (2016) 89:586600. doi: 10.1016/j.kint.2015.12.029

148. Mencke R, Olauson H, Hillebrands J-L. Effects of Klotho on fibrosis and cancer: a renal focus on mechanisms and therapeutic strategies. Adv Drug Deliv Rev. (2017) 121:85-100. doi: 10.1016/j.addr.2017.07.009

149. Wu $\mathrm{H}$, Humphreys $\mathrm{BD}$. The promise of single-cell RNA sequencing for kidney disease investigation. Kidney Int. (2017) 92:1334-42. doi: 10.1016/j.kint.2017.06.033

150. Insogna KL, Briot K, Imel EA, Kamenický P, Ruppe MD, Portale AA, et al. A randomized, double-blind, placebo-controlled, phase 3 trial evaluating the efficacy of burosumab, an anti-FGF23 antibody, in adults with X-linked hypophosphatemia: week 24 primary analysis: efficacy of burosumab in adults with XLH. J Bone Miner Res. (2018) 33:138393. doi: $10.1002 / \mathrm{jbmr} .3475$

151. Carpenter TO, Whyte MP, Imel EA, Boot AM, Högler W, Linglart A, et al. Burosumab therapy in children with X-linked hypophosphatemia. $N$ Engl J Med. (2018) 378:1987-98. doi: 10.1056/NEJMoa1714641

152. Shalhoub V, Shatzen EM, Ward SC, Davis J, Stevens J, Bi V, et al. FGF23 neutralization improves chronic kidney disease-associated hyperparathyroidism yet increases mortality. J Clin Invest. (2012) 122:254353. doi: $10.1172 /$ JCI61405

153. Castillo-Garzón MJ, Ruiz JR, Ortega FB, Gutiérrez Á. Anti-aging therapy through fitness enhancement. Clin Interv Aging. (2006) 1:21320. doi: $10.2147 /$ ciia.2006.1.3.213

154. Simpson RJ, Guy K. Coupling aging immunity with a sedentary lifestyle: has the damage already been done? - A mini-review. Gerontology. (2010) 56:449-58. doi: 10.1159/000270905

155. Shefer G, Rauner G, Yablonka-Reuveni Z, Benayahu D. Reduced satellite cell numbers and myogenic capacity in aging can be alleviated by endurance exercise. PLoS ONE. (2010) 5:e13307. doi: 10.1371/journal.pone.00 13307

156. Palmefors H, DuttaRoy S, Rundqvist B, Börjesson M. The effect of physical activity or exercise on key biomarkers in atherosclerosis - a systematic review. Atherosclerosis. (2014) 235:150-61. doi: 10.1016/j.atherosclerosis.2014.04.026

157. Slentz CA, Tanner CJ, Bateman LA, Durheim MT, Huffman KM, Houmard JA, et al. Effects of exercise training intensity on pancreatic -cell function. Diabetes Care. (2009) 32:1807-11. doi: 10.2337/dc0 9-0032

158. Crasto CL, Semba RD, Sun K, Cappola AR, Bandinelli S, Ferrucci L. Relationship of low-circulating "anti-aging" Klotho hormone with disability in activities of daily living among older community-dwelling adults. Rejuvenation Res. (2012) 15:295-301. doi: 10.1089/rej.2011.1268
159. Yamamoto M, Clark JD, Pastor JV, Gurnani P, Nandi A, Kurosu H, et al. Regulation of oxidative stress by the anti-aging hormone Klotho. J Biol Chem. (2005) 280:38029-34. doi: 10.1074/jbc.M509039200

160. Semba RD, Cappola AR, Sun K, Bandinelli S, Dalal M, Crasto $\mathrm{C}$, et al. Plasma Klotho and cardiovascular disease in adults: Klotho and cardiovascular disease. J Am Geriatr Soc. (2011) 59:1596-601. doi: 10.1111/j.1532-5415.2011.03558.x

161. Phelps M, Pettan-Brewer C, Ladiges W, Yablonka-Reuveni Z. Decline in muscle strength and running endurance in Klotho deficient C57BL/6 mice. Biogerontology. (2013) 14:729-39. doi: 10.1007/s10522-013-9447-2

162. Avin KG, Coen PM, Huang W, Stolz DB, Sowa GA, DubÃ@ JJ, et al. Skeletal muscle as a regulator of the longevity protein, Klotho. Front Physiol. (2014) 5:189. doi: 10.3389/fphys.2014.00189

163. Saghiv MS, Sira DB, Goldhammer E, Sagiv M. The effects of aerobic and anaerobic exercises on circulating soluble-Klotho and IGF-I in young and elderly adults and in CAD patients. J Circ Biomark. (2017) 6:184945441773338. doi: 10.1177/1849454417733388

164. Mostafidi E, Moeen A, Nasri H, Ghorbani Hagjo A, Ardalan M. Serum Klotho levels in trained athletes. NephroUrol Mon. (2016) 8:e30245. doi: 10.5812/numonthly. 30245

165. Pako J, Barta I, Balogh Z, Kerti M, Drozdovszky O, Bikov A, et al. Assessment of the anti-aging Klotho protein in patients with COPD undergoing pulmonary rehabilitation. COPD J Chronic Obstr Pulm Dis. (2017) 14:17680. doi: $10.1080 / 15412555.2016 .1272563$

166. Shardell M, Semba RD, Rosano C, Kalyani RR, Bandinelli S, Chia CW, et al. Plasma Klotho and cognitive decline in older adults: findings from the InCHIANTI study. J Gerontol A Biol Sci Med Sci. (2016) 71:67782. doi: 10.1093/gerona/glv140

167. Semba RD, Cappola AR, Sun K, Bandinelli S, Dalal M, Crasto C, et al. Relationship of low plasma Klotho with poor grip strength in older community-dwelling adults: the InCHIANTI study. Eur J Appl Physiol. (2012) 112:1215-20. doi: 10.1007/s00421-011-2072-3

168. Brownstein CA, Adler F, Nelson-Williams C, Iijima J, Li P, Imura A, et al. A translocation causing increased -Klotho level results in hypophosphatemic rickets and hyperparathyroidism. Proc Natl Acad Sci USA. (2008) 105:345560. doi: 10.1073/pnas.0712361105

169. Adema AY, Vervloet MG, Blankenstein MA, Heijboer AC, on behalf of the NIGRAM Consortium. $\alpha$-Klotho is unstable in human urine. Kidney Int. (2015) 88:1442-4. doi: 10.1038/ki.2015.238

170. Gregg LP, Hedayati SS. Management of traditional cardiovascular risk factors in CKD: what are the data? Am J Kidney Dis. (2018) 72:72844. doi: 10.1053/j.ajkd.2017.12.007

171. McClelland R, Christensen K, Mohammed S, McGuinness D, Cooney J, Bakshi A, et al. Accelerated ageing and renal dysfunction links lower socioeconomic status and dietary phosphate intake. Aging. (2016) 8:113549. doi: 10.18632/aging.100948

172. Chang AR, Lazo M, Appel LJ, Gutiérrez OM, Grams ME. High dietary phosphorus intake is associated with all-cause mortality: results from NHANES III. Am J Clin Nutr. (2014) 99:320-7. doi: 10.3945/ajcn.113.073148

173. Yoo KD, Kang S, Choi Y, Yang SH, Heo NJ, Chin HJ, et al. Sex, age, and the association of serum phosphorus with all-cause mortality in adults with normal kidney function. Am J Kidney Dis. (2016) 67:7988. doi: 10.1053/j.ajkd.2015.06.027

174. Kawai M, Kinoshita S, Ozono K, Michigami T. Inorganic phosphate activates the AKT/mTORC1 pathway and shortens the life span of an $\alpha$-Klotho-deficient model. J Am Soc Nephrol. (2016) 27:281024. doi: 10.1681/ASN.2015040446

175. Di Iorio B, Di Micco L, Torraca S, Sirico ML, Russo L, Pota A, et al. Acute effects of very-low-protein diet on FGF23 levels: a randomized study. Clin J Am Soc Nephrol. (2012) 7:581-7. doi: 10.2215/CJN.07640711

176. Milovanova L, Fomin V, Moiseev S, Taranova M, Milovanov Y, Lysenko L, et al. Effect of essential amino acid? etoanalogues and protein restriction diet on morphogenetic proteins (FGF-23 and? lotho) in $3 \mathrm{~b}-4$ stages chronic kidney disease patients: a randomized pilot study. Clin Exp Nephrol. (2018) 22:1351-9. doi: 10.1007/s10157-018-1591-1

177. Yoshikawa R, Yamamoto H, Nakahashi O, Kagawa T, Tajiri M, Nakao $\mathrm{M}$, et al. The age-related changes of dietary phosphate responsiveness in plasma 1,25-dihydroxyvitamin D levels and renal Cyp27b1 and Cyp24al 
gene expression is associated with renal $\alpha$-Klotho gene expression in mice. J Clin Biochem Nutr. (2018) 62:68-74. doi: 10.3164/jcbn.17-20

178. Courbon G, Martinez-Calle M, David V. Simultaneous management of disordered phosphate and iron homeostasis to correct fibroblast growth factor 23 and associated outcomes in chronic kidney disease. Curr Opin Nephrol Hypertens. (2020) 29:359-66. doi: 10.1097/MNH.0000000000000614

179. Coppolino G, Nicotera R, Cernaro V, Calimeri S, Leonardi G, Cosentino $\mathrm{S}$, et al. Iron infusion and induced hypophosphatemia: the role of fibroblast growth factor-23. Ther Apher Dial. (2020) 24:258-64. doi: 10.1111/1744-9987.13435

180. Francis C, Courbon G, Gerber C, Neuburg S, Wang X, Dussold C, et al. Ferric citrate reduces fibroblast growth factor 23 levels and improves renal and cardiac function in a mouse model of chronic kidney disease. Kidney Int. (2019) 96:1346-58. doi: 10.1016/j.kint.2019. 07.026

181. ter Braake AD, Smit AE, Bos C, van Herwaarden AE, Alkema W, van Essen HW, et al. Magnesium prevents vascular calcification in Klotho deficiency. Kidney Int. (2020) 97:487-501. doi: 10.1016/j.kint.2019.09.034

182. Maguire D, Neytchev O, Talwar D, McMillan D, Shiels P. Telomere homeostasis: interplay with magnesium. Int J Mol Sci. (2018) 19:157. doi: 10.3390/ijms19010157

183. Pool LR, Kershaw KN, Gordon-Larsen P, Gutiérrez OM, Reis JP, Isakova $\mathrm{T}$, et al. Racial differences in the associations between food insecurity and fibroblast growth factor 23 in the coronary artery risk development in young adults study. J Ren Nutr. (2020). doi: 10.1053/j.jrn.2020.01.020. [Epub ahead of print].

184. Glosse P, Fajol A, Hirche F, Feger M, Voelkl J, Lang F, et al. A high-fat diet stimulates fibroblast growth factor 23 formation in mice through TNF $\alpha$ upregulation. Nutr Diabetes. (2018) 8:36. doi: 10.1038/s41387-018-0037-x

185. Lin Y, Chen J, Sun Z. Antiaging gene Klotho deficiency promoted high-fat diet-induced arterial stiffening via inactivation of AMP-activated protein kinase. Hypertension. (2016) 67:56473. doi: 10.1161/HYPERTENSIONAHA.115.06825

186. Trummer C, Schwetz V, Pandis M, Grübler MR, Verheyen N, Gaksch M, et al. Effects of vitamin D supplementation on FGF23: a randomized-controlled trial. Eur J Nutr. (2019) 58:697-703. doi: 10.1007/s00394-018-1672-7

187. Charoenngam N, Rujirachun P, Holick MF, Ungprasert P. Oral vitamin D3 supplementation increases serum fibroblast growth factor 23 concentration in vitamin D-deficient patients: a systematic review and meta-analysis. Osteoporos Int. (2019) 30:2183-93. doi: 10.1007/s00198-019-05102-7

188. Jurado-Fasoli L, Amaro-Gahete FJ, De-la-O A, Gutiérrez Á, Castillo MJ. Alcohol consumption and S-Klotho plasma levels in sedentary healthy middle-aged adults: a cross sectional study. Drug Alcohol Depend. (2019) 194:107-11. doi: 10.1016/j.drugalcdep.2018.09.024

189. Hsu S-C, Huang S-M, Chen A, Sun C-Y, Lin S-H, Chen J-S, et al. Resveratrol increases anti-aging Klotho gene expression via the activating transcription factor 3/c-Jun complex-mediated signaling pathway. Int J Biochem Cell Biol. (2014) 53:361-71. doi: 10.1016/j.biocel.2014.06.002

190. Jurado-Fasoli L, Castillo MJ, Amaro-Gahete FJ. Dietary inflammatory index and s-Klotho plasma levels in middle-aged adults. Nutrients. (2020) 12:281. doi: 10.3390/nu12020281

191. Jurado-Fasoli L, Amaro-Gahete FJ, De-la-O A, Martinez-Tellez B, Ruiz JR, Gutiérrez Á, et al. Adherence to the Mediterranean diet, dietary factors, and s-Klotho plasma levels in sedentary middle-aged adults. Exp Gerontol. (2019) 119:25-32. doi: 10.1016/j.exger.2019.01.019

192. Rouhani MH, Mortazavi Najafabadi M, Surkan PJ, Esmaillzadeh A, Feizi A, Azadbakht L. The impact of oat (Avena sativa) consumption on biomarkers of renal function in patients with chronic kidney disease: a parallel randomized clinical trial. Clin Nutr. (2018) 37:7884. doi: 10.1016/j.clnu.2016.11.022

193. Mafra D, Esgalhado M, Borges NA, Cardozo LFMF, Stockler-Pinto MB, Craven $\mathrm{H}$, et al. Methyl donor nutrients in chronic kidney disease: impact on the epigenetic landscape. J Nutr. (2019) 149:372-80. doi: 10.1093/jn/ nxy 289

194. Stenvinkel P, Meyer CJ, Block GA, Chertow GM, Shiels PG. Understanding the role of the cytoprotective transcription factor nuclear factor erythroid 2-related factor 2-lessons from evolution, the animal kingdom and rare progeroid syndromes. Nephrol Dial Transplant. (2019) gfz120. doi: 10.1093/ndt/gfz120

195. Bora SA, Kennett MJ, Smith PB, Patterson AD, Cantorna MT. Regulation of vitamin D metabolism following disruption of the microbiota using broad spectrum antibiotics. J Nutr Biochem. (2018) 56:65-73. doi: 10.1016/j.jnutbio.2018.01.011

Conflict of Interest: The authors declare that the research was conducted in the absence of any commercial or financial relationships that could be construed as a potential conflict of interest

Copyright $\odot 2020$ Buchanan, Combet, Stenvinkel and Shiels. This is an open-access article distributed under the terms of the Creative Commons Attribution License (CC $B Y)$. The use, distribution or reproduction in other forums is permitted, provided the original author(s) and the copyright owner(s) are credited and that the original publication in this journal is cited, in accordance with accepted academic practice. No use, distribution or reproduction is permitted which does not comply with these terms. 